\title{
2D dynamic studies combined with the surface curvature analysis to predict Arias Intensity amplification
}

\author{
Almaz Torgoev • Hans-Balder Havenith
}

Received: 7 April 2015 / Accepted: 13 January 2016

C) Springer Science+Business Media Dordrecht 2016

\begin{abstract}
A 2D elasto-dynamic modelling of the pure topographic seismic response is performed for six models with a total length of around $23.0 \mathrm{~km}$. These models are reconstructed from the real topographic settings of the landslide-prone slopes situated in the Mailuu-Suu River Valley, Southern Kyrgyzstan. The main studied parameter is the Arias Intensity (Ia, $\mathrm{m} / \mathrm{sec}$ ), which is applied in the GIS-based Newmark method to regionally map the seismically-induced landslide susceptibility. This method maps the Ia values via empirical attenuation laws and our studies investigate a potential to include topographic input into them. Numerical studies analyse several signals with varying shape and changing central frequency values. All tests demonstrate that the spectral amplification patterns directly affect the amplification of the Ia values. These results let to link the $2 \mathrm{D}$ distribution of the topographically amplified Ia values with the parameter called as smoothed curvature. The amplification values for the low-frequency signals are better correlated with the curvature smoothed over larger spatial extent, while those values for the high-frequency signals are more linked to the curvature with smaller smoothing extent. The best predictions are provided by the curvature
\end{abstract}

\footnotetext{
A. Torgoev $\cdot$ H.-B. Havenith

Georisks and Environment, Department of Geology, University of Liege, 4000 Liege, Belgium

A. Torgoev $(\bowtie)$

GEOPRIBOR, Institute of Geomechanics and Development of Subsoil, 720035 Bishkek, Kyrgyz Republic

e-mail: torgoeval@yahoo.com
}

smoothed over the extent calculated according to Geli's law. The sample equations predicting the Ia amplification based on the smoothed curvature are presented for the sinusoid-shape input signals. These laws cannot be directly implemented in the regional Newmark method, as 3D amplification of the Ia values addresses more problem complexities which are not studied here. Nevertheless, our 2D results prepare the theoretical framework which can potentially be applied to the $3 \mathrm{D}$ domain and, therefore, represent a robust basis for these future research targets.

Keywords Kyrgyzstan · Mailuu-Suu · Landslides · Elasto-dynamic modelling $\cdot$ Newmark method $\cdot$ Arias Intensity $\cdot$ Topographic amplification $\cdot$ Smoothed curvature

\section{Introduction}

According to Keefer (2002) and Jibson (2007), most moderate and large earthquakes trigger landslides in mountain regions. These landslides often account for a significant proportion of total infrastructural damage and death toll. For instance, the $\mathrm{Mw}=7.3 \mathrm{Chi}-\mathrm{Chi}$, Taiwan earthquake in 1999 triggered more than 20,000 landslides, bringing significant infrastructural damage and $10 \%$ of all earthquake fatalities (Lin et al. 2003). For the $\mathrm{Mw}=7.6 \mathrm{Kashmir}$ earthquake in 2005, about $30 \%$ of all earthquake fatalities are related to the coseismic landslides, i.e. 26,500 victims out of the 87,350 total death toll (Petley et al. 2006). One of the latest and 
most illustrative examples is presented by the $\mathrm{Mw}=7.9$ Wenchuan earthquake in 2008 in Sichuan Province, China. According to Gorum et al. (2011), this earthquake triggered at least 60,000 landslides. Yin et al. (2009) attributed about 20,000 fatalities to the effects of co-seismic landslides, which is near one-third of the official estimate of 69,197 deaths.

As the co-seismic landslides often bring significant damage and associated fatalities, the issues related to the regional prediction of those landslides attracts significant attention. The GIS-based Newmark method is among the most applied approaches to regionally assess the co-seismically induced slope displacements. The concept of the method has evolved from a simplified model proposed by Newmark (1965). This model proposes to calculate the co-seismic displacement of a rigid block sliding on an inclined plane through the double integration of the impacting acceleration-time history. The core point of the proposed technique implies that only the part of the acceleration-time history, exceeding the critical acceleration value (Ac), should be subjected to the integration. This last parameter (Ac) is directly dependent on the static Factor of Safety (FS) of a studied slope as follows:

$\mathrm{Ac}=(\mathrm{FS}-1) * g * \sin \alpha$

where $g\left(\mathrm{~m} / \mathrm{sec}^{2}\right)$ is the acceleration due to gravity and $\alpha\left(^{\circ}\right)$ is the slope angle. The calculation of the FS values can be performed via any conventional slope stability assessment, e.g. applying the Janbu (1973) method.

Originally, the Newmark (1965) model was applied for the stability analyses of dams and embankments at the scale of a single slope. The main reason constraining its application to a local scale is the difficulty to get a regional distribution of the input parameters (Ac, acceleration-time histories), which is a prerequisite for the regional studies.

A series of modified concepts, that may be referred to as the regional Newmark models, have overcome this limitation. The earliest models are proposed by Wilson and Keefer (1985), Wieczorek et al. (1985), Ambraseys and Menu (1988) and Jibson (1993). The last model, i.e. the one presented by Jibson (1993), became the basis for later developments (e.g. Ambraseys and Srbulov 1995;
Crespellani et al. 1996; Jibson et al. 1998; Miles and Ho 1999; Hsieh and Lee 2007 among others). It maps the values of the co-seismic displacement (Dn, cm) as follows:

$\log \mathrm{Dn}=1.460 \log \mathrm{Ia}-6.642 \mathrm{Ac}+1.546 \pm 0.409$,

where Ia is the value of the Area Intensity for the impacting seismic shaking (in $\mathrm{m} / \mathrm{sec}$ ) and Ac is the critical acceleration (in terms of $g$ ).

More recent developments in this domain apply more complicated laws, where the co-seismic displacement value additionally depends on different ground motion parameters (Saygili and Rathje 2008; Rathje and Saygili 2009), the natural period of the sliding mass and the mean period of the earthquake motion (Rathje and Antonakos 2011). Nevertheless, the majority of laws predict the co-seismic slope displacement based on two main factors shown in Eq.(2), i.e. based on Ia and Ac. The values of Ac in this case are assessed according to Eq.(1), when the FS values are calculated by the Janbu (1973) method based on the spatial distribution of the involved geotechnical parameters (i.e. cohesion, internal friction angle, etc.). At present, this mapping proxy is adopted by most of the models and does not have any sound alternatives.

Another important parameter applied by most of the laws is the Arias Intensity (Ia, $\mathrm{m} / \mathrm{sec}$ ). This parameter is first introduced by Arias (1970) and is given in the next equation:

$\mathrm{Ia}=\frac{\pi}{2 * g} * \int_{0}^{T_{\mathrm{d}}}[a(t)] d t$

where $a(t)$ is a single component acceleration-time series $\left(\mathrm{m} / \mathrm{sec}^{2}\right), T_{\mathrm{d}}$ is the total duration of acceleration recording (sec), $t$ is the time (s) and $g$ is the acceleration of gravity.

Wilson and Keefer (1985) are the first to propose an empirical law for a regional mapping of the Ia values. In this so-called Arias Intensity attenuation law the Ia value is correlated to the earthquake magnitude $(M)$ and the epicentral distance $(R, \mathrm{~km})$ :

$\log \mathrm{Ia}=K_{0}+K_{\mathrm{M}} * M-2 * \log R+K_{\mathrm{c}} * P$

where $K_{0}$ and $K_{\mathrm{M}}$ are the proportionality constants, $K_{\mathrm{C}}$ is the standard deviation for Ia values, and $P$ is the exceedance probability. 
Since then several authors have proposed various attenuation laws such as, e.g. Wald et al. (1990), Harp and Wilson (1995), Mahdavifar et al. (2007), Rajabi et al. (2010), Lee et al. (2012) among others. While some of these laws estimate the value of Ia based on two predictors cited in Eq.(4), the most advanced relationships try to account for more problem complexities. For example, several laws account for the deamplification/amplification impacts of surface geology via the shear-wave velocity in the upper layer (see, e.g. Travasarou et al. 2003) or through the site variables reflecting the soil/rock site composition (see, e.g. Sabetta and Pugliese 1996; Rathje et al. 2004; Romeo 2000; Stafford et al. 2009; Chousianitis et al. 2014).

Nevertheless, none of the published laws consider the inputs created by the topographic site effects. Meanwhile, Peng et al. (2009) through the numerical studies show that the topographic site effects can significantly modify the values of Ia. The authors demonstrate that Ia values at the top of a given hill can be up to 3-4 times more than Ia at its base. The role of topographic amplification in the triggering of the slope movement is shown by Densmore and Hovious (2000), Harp and Jibson (2002), Sidle and Ochiai (2006), Sepulveda et al. (2005), Meunier et al. (2008) and Yin et al. (2009) among others.

Several authors consider the topographic effect within the single slope Newmark method (see, e.g. Seed and Martin 1966; Makdisi and Seed 1978; Rathje and Bray 2000; Bray and Travasarou 2007). These models account for the slope geometry during the calculation of the co-seismic displacement values. The involved morphologic parameters cannot be easily integrated into the regional analyses which suggest that a way to include the topographic input into the conventional mapping practice still remains unclear.

One possible way to account for those topographic inputs is presented by Torgoev et al. (2013b). The authors show that the pure topographic Ia amplification factors can be predicted by the topographic curvature. That link is proven through the 2D dynamic tests with a single value of central frequency, while signals with varying spectral content are not studied. Meanwhile, Maufroy et al. (2015) apply the surface curvature in a modified way to regionally predict the spectral amplification patterns. The authors performed a set of dynamic tests in the 3D domain and show that amplified frequency range can be predicted via the parameter known as the frequency-scaled curvature (FSC). These studies show that the spectral amplification and the amplification of Ia values are bound together. Such links are also confirmed by Stafford et al. (2009) who relate the value of Ia to the set of seismological descriptors, including the central frequency of shaking.

In this paper, we investigate those links in more details. It is performed via the analysis of the $2 \mathrm{D} \mathrm{dy-}$ namic recordings acquired along six extended models. These recordings reflect the patterns of the topographic site effects, as the surface of models is reconstructed from the real topography. The main analysed parameter is Ia which is calculated based on recorded accelerationtime histories. The dynamic simulations study several signals of varying shape and changing central frequency value. Based on recorded data we demonstrate how the spectral amplification is related to the amplification of the Ia values. Additionally, we investigate how the curvature smoothed over a specific neighbourhood can predict the Ia amplification factors. This analysis yields sample relationships where the Ia amplification factors are predicted by the smoothed curvature values. These relationships cannot be directly applied to map the amplification factors in 3D domain, as the presence of two horizontal components in 3D meets additional problem complexities. Nevertheless, our 2D results propose a concept which can be further applied to the 3D domain and, thus, prepare the framework to incorporate the topographic inputs into the conventional mapping practice.

\section{Target area}

The Mailuu-Suu River Valley (see M-S in Fig. 1) is situated in the south of the Kyrgyz Tien Shan, which is a Cenozoic orogenic belt and one of the most tectonically and seismically active intra-plate regions of the world (Giardini et al. 1999). Several strong earthquakes struck the Tien Shan and its surroundings during the last century, including the strongest ones, like the $M=8.2$ Kemin earthquake in 1911 (see event 1 in Fig. 1), the $M=7.6$ Chatkal earthquake in 1946 (see event 2), the $M=7.4$ Khait earthquake in 1949 (see event 3) and the $M=7.3$ Suusamyr earthquake in 1992 (see event 4). The Mailuu-Suu River Valley is marked by a moderate to high level of seismic hazard - the last strong earthquake $(\mathrm{Ms}=6.2)$ hit the region on May 15, 1992; it was located about $30 \mathrm{~km}$ SSE of the Mailuu-Suu town (Abdrakhmatov et al. 2003; Havenith et al. 2006). 


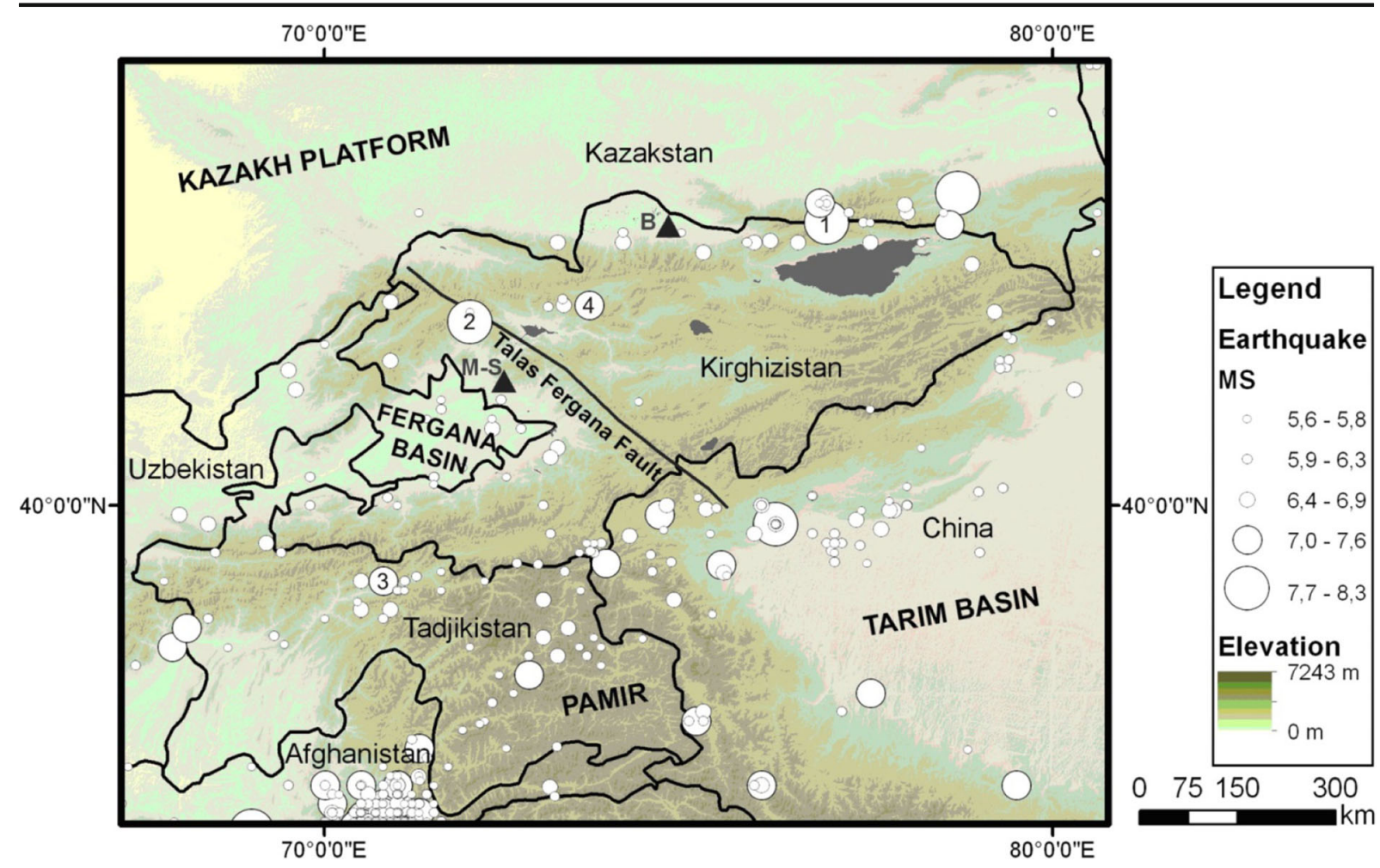

Fig. 1 Topographic map of the Kyrgyz Tien Shan and neighbouring regions with indicated location of the Bishkek (B) and the Maily-Say (M-S) Cities; event 1 is the $M=8.2$ Kemin earthquake in 1911, event 2 is the $M=7.6$ Chatkal earthquake in

The target area is characterised by a combination of geologic, tectonic and climatic settings favouring intense landslide activity in this area (Alioshin and Torgoev 2000; Torgoev et al. 2002; Torgoev and Havenith 2013b). The landscape in the Mailuu-Suu River Valley is continuously changing owing to the high landslide activity. The total area affected by landslides increased more than five times in the period between 1962 and 2007 (Havenith et al. 2006). The studies also indicate that the absolute number of large and very large landslides increases over time, while the number of small landslides decreases proportionally (Schlögel et al. 2011).

There are several landslides in the target area, which are likely to be related to a partial co-seismic slope failure. One of the biggest disasters occurred when the Tektonik landslide (see Fig. 2a) failed on July 4, 1992it was 7 weeks after the Ms $=6.2$ earthquake (May 15, 1992) mentioned previously. This landslide with a volume of $1.5 \times 10^{6} \mathrm{~m}^{3}$ brought significant economic losses and caused sensitive environmental damage (Vandenhove et al. 2003). It is very likely that this
1946, event 3 is the $M=7.4$ Khait earthquake in 1949 and event 4 is the $M=7.3$ Suusamyr earthquake in 1992; the fault trace is according to Trifonov et al. 1990 (by Schlögel et al. 2011).

seismic event was one of the main preparatory factors for the landslide failure (Havenith et al. 2006).

After the catastrophe of the Tektonik landslide, an extensometric monitoring system was installed in 1997 in some critical sites, including the Upper Koytash landslide (see a monitoring area marked by a red point in Fig. 2a; Torgoev et al. 2013a). The monitoring results show that a fracture of several tens of centimetres had opened after two distant $(>100 \mathrm{~km})$ earthquakes $(M=5.9$ and 6.0) that occurred in the beginning of 1997 (see Fig. 2b). The Upper Koytash landslide finally failed in 2005 to produce a $700 \mathrm{~m}$ long earthflow made of loess. This final failure was mainly triggered by precipitation.

The monitoring results demonstrate that seismic activity could be one of the main preparatory factors for the following landslide failure (see the evidence at the end of 1997 in Fig. 2b). Meanwhile, the nature of associated processes remains unclear. The failure of the Tektonik landslide in 1992 was preceded by a strong $(\mathrm{Ms}=6.2)$ earthquake located at a distance of $30-40 \mathrm{~km}$ from the site - the dynamic impact of this earthquake 


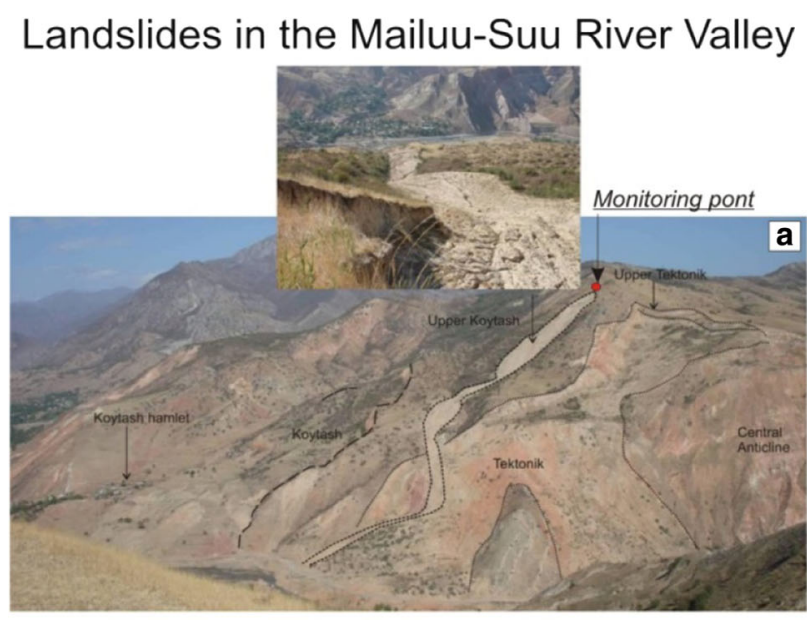

Fig. 2 a General view (September, 2008) at the eastern part of the Mailuu-Suu River Valley with location of Koytash, Upper Koytash, Tektonik and other landslides (the Upper Koytash monitoring area is marked by the red point); b The results of the Upper

caused extensive cracking all over the slope, while the subsequent precipitation lead to the final loss of stability (Torgoev et al. 2013a). Meanwhile, the Upper Koytash landslide did not respond to local seismic activity before the final failure, while it clearly moved during two distant earthquakes in 1997.

Such remote effects are mentioned by several authors working in neighbouring areas. For instance, Torgoev et al. (2013d) explained it by a particular interaction of the local topography with low-frequency seismic shaking arriving from distant earthquake events. Keefer (2002) listed several world-wide cases, when slope failures were triggered at epicentral distances of more than $100-120 \mathrm{~km}$ - it was proposed that local site amplification could be the main triggering factor in these particular examples. A full explanation of this phenomenon needs coupling of field measurements with combined topographic-geological modelling. Part of this research problem is tackled by our studies, as one of the studied profiles crosses the mountain of the Upper Koytash landslide.

\section{Applied numerical software}

The numerous field and research data collected for our study area allowed us to construct well-defined models of the landslide-prone slopes. These models are further used for numerical analyses of seismic effects. They are performed with the modelling software known as the

\section{Upper Koytash: Monitoring results vs Seismic activity}

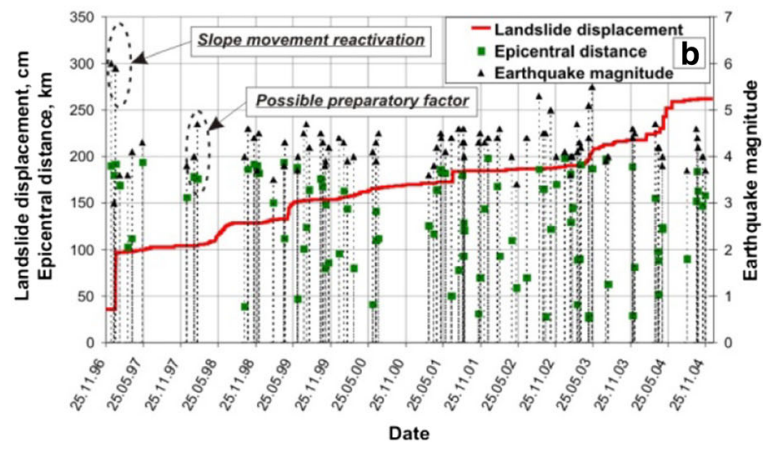

Koytash landslide monitoring (extensometric data) plotted versus seismic activity for a period from 25.11.1996 until 25.11.2004 (by Torgoev et al. 2013a).

Universal Distinct Element Code (ITASCA UDEC, version 4.01). This code can simulate the response of continuous and discontinuous media (e.g. jointed rock mass) subjected to either static or dynamic loading (Itasca 2006). The media is represented by an assemblage of rigid/deformable blocks which are separated by the contacts with possibility of large displacement along them. These blocks are subdivided into a mesh of finitedifference (FD) elements and each element responds according to a prescribed linear or nonlinear stressstrain law. The recordings of the different dynamical parameters (e.g. acceleration, velocity or displacement) can be performed in any part of the studied medium. Due to these possibilities the UDEC code is considered to be a very powerful tool for the $2 \mathrm{D}$ modelling of seismic energy propagation. Possibilities for large contact displacements and an option for the plastic behaviour provide additional perspectives for the landslide related studies. Nevertheless, all our simulations are run in the elastic domain, as we focus on the study of a linear seismic response.

\section{Model construction and dynamic modelling settings}

The topographic models of the landslide-prone slopes are constructed on the basis of the SPOT DEM with a cell size of $21 \times 21 \mathrm{~m}$ (Schlögel et al. 2011). Figure 3 presents the topographic map/DEM of the target area, 

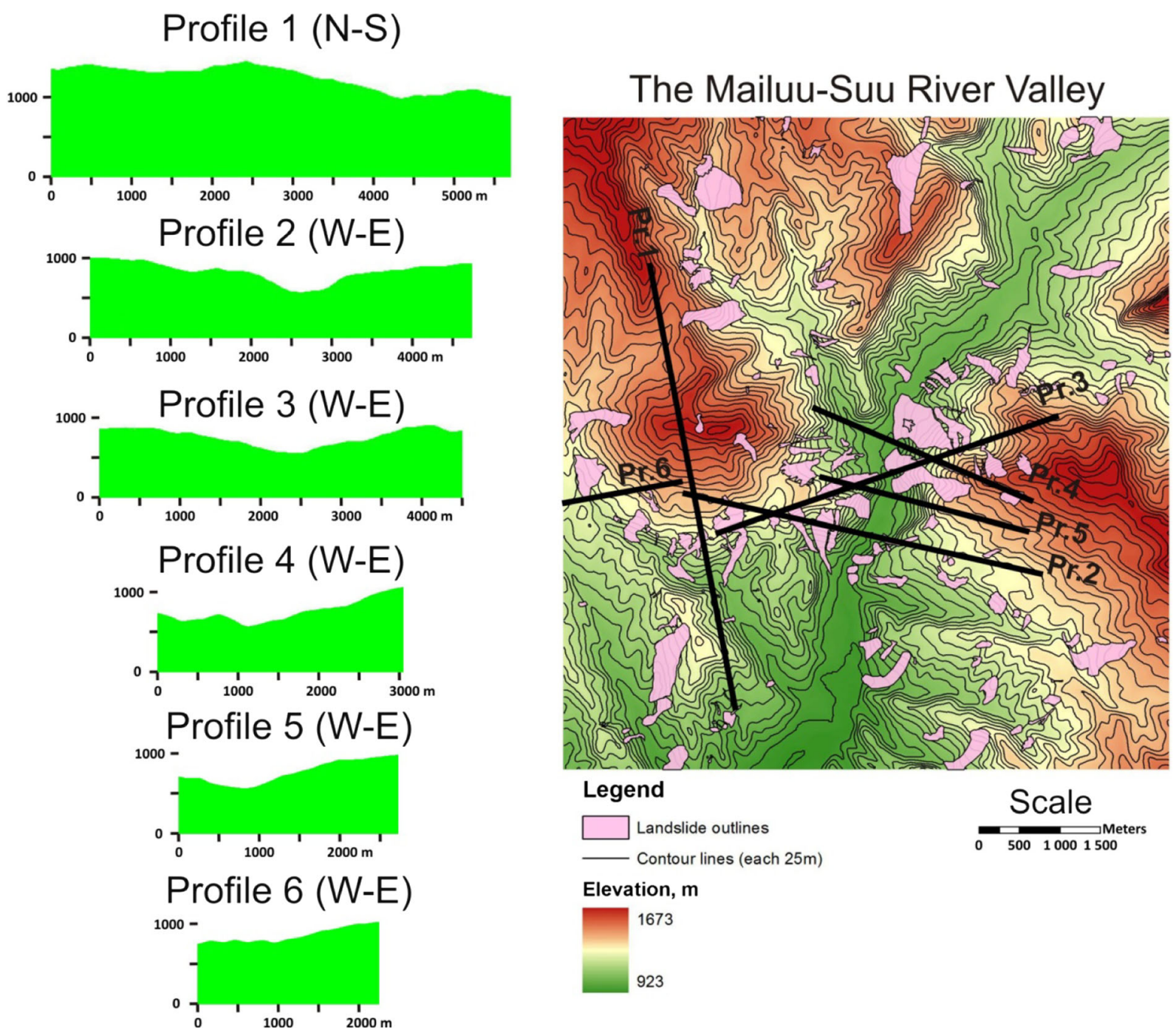

Fig. 3 The DEM of target area together with landslide outlines, studied profiles and constructed models applied for the 2D elasto-dynamic modelling.

six studied profiles and the related set of constructed models. The total length of these models is around $23.0 \mathrm{~km}$, while each model has a minimum length of $2.0 \mathrm{~km}$. A larger model extent allows us to reduce the reflection/refraction boundary effects and to track amplification patterns associated with a larger variety of morphologies. The curvature values for the $42 \mathrm{~m}$ baseline length (the DEM pixel resolution of $21 \mathrm{~m}$ ) span from -0.2 up to 0.5 (in terms of general curvature-see details in the "Curvature, FSC and smoothed curvature" section). Profiles 4, 5 and 6 cross some of the well-known landslides in the target area, including the Upper Koytash (profile 4) and the Tektonik (profile 5) landslides. Profiles 1, 2 and 3 reflect the basic morphologic features marking the target area (river valley, mountain crest, curved morphology, inclined slopes, etc.).

To simulate the pure topographic effects we apply an unique material type represented mainly by compacted Cretaceous sandstone (de Marneffe 2010). The mean values of geophysical-geotechnical properties (Vs $=1300 \mathrm{~m} / \mathrm{sec}, \mathrm{Vp}=2500 \mathrm{~m} / \mathrm{sec}$ and $\rho=2200 \mathrm{~kg} /$ m3) are estimated on the basis of older reports (Nikitin and Fidelli 1974; Kyrgyzgiiz 1986, etc.) and more recent geophysical studies in the target area (Torgoev et al. 2002; Minetti et al. 2002; Havenith et al. 2006; Torgoev et al. 2012). It should be noted that much more detailed geological data are available for this area, but here we 


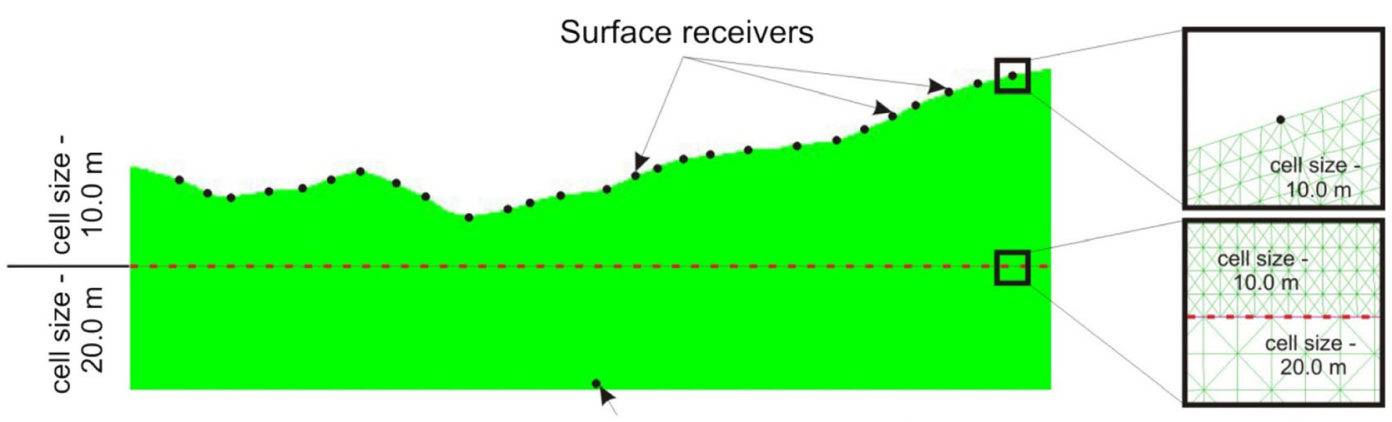

Reference receiver (10 $\mathrm{m}$ above model bottom)

Fig. 4 The size of the FD-zones and position of the receivers applied for all constructed models.

consider only a single material, as we focus on the pure topographic effects.

The models are filled by the FD-zones with variable edge length (see Fig. 4). The upper parts of all models between the surface and a depth of 300-500 $\mathrm{m}$ are filled by $10 \times 10 \mathrm{~m}$ FD-zones. The size of the zones in these parts of models is adapted to the S-wave velocity values according to the criteria proposed by Kuhlmeyer and Lysmer (1973) Thus, for Vs $=1300 \mathrm{~m} / \mathrm{sec}$, the FD-zones with a size of $10 \times 10 \mathrm{~m}$ can correctly propagate seismic energy (shear stress) up to 10.0-12.0 Hz. For a computational efficiency, the FD-zones in the lower parts of models have an edge length of $20 \times 20 \mathrm{~m}$ (see Fig. 4).

Simulated signals are recorded by a large number of receivers distributed over the model surface and located in characteristic sites of curved morphologies: on hill crests, in the mid-slope and depressions (see sample position in Fig. 4). The signals of 186 surface receivers distributed along the surface of six models are analysed and compared with those of a reference receiver situated $10 \mathrm{~m}$ above the bottom of each model (see a position of reference receiver in Fig. 4).

To reduce the effects of reflections from the boundaries, a large model extent (as indicated above) is combined with free-field conditions along the lateral and lower rims. All models have to be numerically stabilised prior to the simulation of seismic energy propagation. It is reached by a cycling in static conditions until the ratio of mechanical force and unbalance force are both less than a value of $10^{-5}$. The stabilised models are subjected to a dynamic loading in a shape of a plane wave impeded from the whole extent of the model bottom. The duration of the signal recording over all surface receivers is set to $15.0 \mathrm{sec}$.

A Ricker shape shear stress wave with two central frequency values $(1.4$ and $3.5 \mathrm{~Hz})$ is applied to all models. Its shape results in a quasi-sinusoid form of $x$ component acceleration-time history (see one in Fig. 5a). This signal form provides a flexible solution to vary the analysed frequency range. For example, the central frequency values of 1.4 and $3.5 \mathrm{~Hz}$ result in the spectral coverage of the $x$-component acceleration-time history to be roughly between 0.3 and $9.0 \mathrm{~Hz}$ (see the spectral amplitude distribution in Fig. 5a). The effective time of dynamic loading in this case does not exceed $1.5 \mathrm{sec}-$ onds and the PGA value is around $2.18 \mathrm{~m} / \mathrm{s}^{2}$ $(\approx 0.22 \mathrm{~g}$; see Fig. $5 \mathrm{a})$. For our elastic tests, the input PGA value is not critical as we focus only on the relative amplification of the ground motions and do not study the destabilising consequences related to the varying values of PGA.
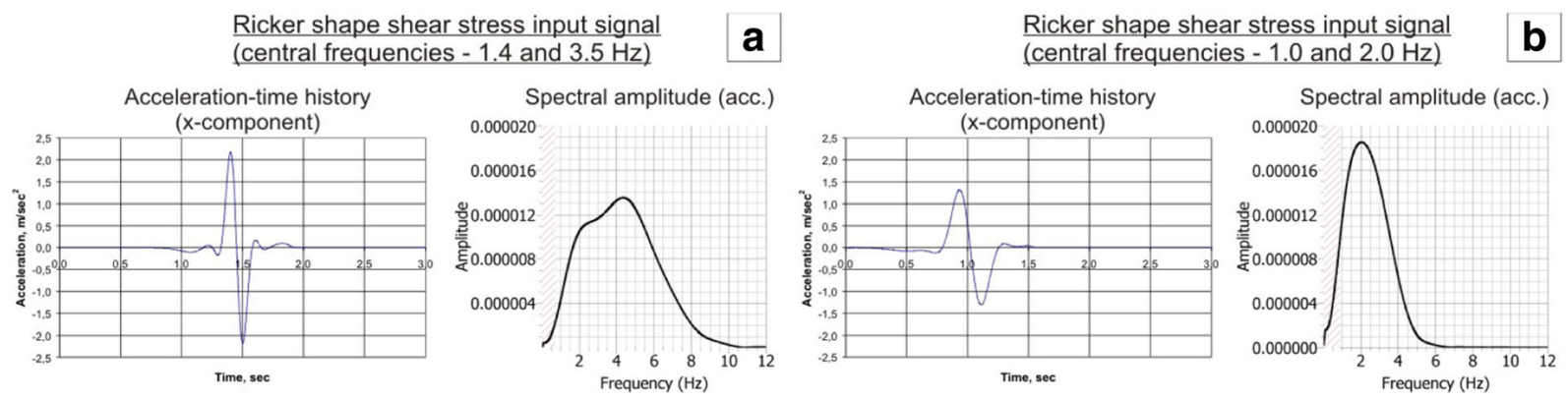

Fig. 5 The $x$-component acceleration-time histories and the corresponding spectral amplitude distribution resulted from two Ricker shape shear stress input signals. 
A model for profile 3 is additionally subjected to the input signals of varying forms and changing frequency content. This is performed to test an influence of the input frequency on the final value of Ia. These signals include the Ricker shape shear stress wave with the central frequencies of 1.0 and $2.0 \mathrm{~Hz}$ (see Fig. 5b), as well as sinusoid-shape shear stress waves (one full cycle) with varying frequency content $(2.0,3.5,5.0$ and $6.0 \mathrm{~Hz})$.

\section{General patterns of the arias intensity amplification}

The topographic amplification is analysed via the values of the Arias Intensity (Ia, m/sec). To characterise this amplification we employ a parameter At $\left(\mathrm{At}_{\mathrm{n}}\right)$, which compares the Ia value obtained at any given surface receiver $\left(\mathrm{Ia}_{\mathrm{n}}\right)$ with the one of reference receiver $\left(\mathrm{Ia}_{0}\right)$ :

$\mathrm{At}_{\mathrm{n}}=\frac{\mathrm{Ia}_{\mathrm{n}}}{\mathrm{Ia}_{0}}$

According to Eq.(3), the Ia values for all receivers $\left(\mathrm{Ia}_{\mathrm{n}}\right.$ and $\left.\mathrm{Ia}_{0}\right)$ are calculated by the integration of a squared acceleration-time history ( $x$-component). Eq.(5) only applies the horizontal component of the Ia values, while the vertical component is not analysed. This choice is related to the fact that destabilising input of the vertical component is often considered to be negligible and, therefore, is not taken into account. For example, Harp and Wilson (1995) commented that most vertical strong-motion records bring a relatively small input into the total energy of recorded shaking and, thus, can be ignored in the analysis. Meanwhile, in the 3D domain with two horizontal components the analyses usually apply either the sum of both components or the largest value out of them (see, e.g. Del Gaudio and Wasowski 2011; Chousianitis et al. 2014)

In Eq. (5) the surface acceleration-time histories are analysed in their original way, while reference histories are modified prior to integration. All reference recordings are multiplied by 2 to compensate the free-surface amplification effect usually observed on all surface receivers (see more details in Lee et al. 2003). This value of amplification factor is also confirmed by our tests with simplified model geometry.

Figure 6 presents a distribution of the At values observed for the four longest profiles (profile 1, 2, 3 and 4) applying Ricker shape shear stress input signal $(1.4$ and $3.5 \mathrm{~Hz})$. As it can be seen, all crest parts of curved morphologies are characterised by amplified values of At, while the central parts of concave morphologies are marked by deamplification. It should be noted, that we consider the general curvature, when the hill/mountain is convex, while the valley is concave. An analysis of modelling results indicates that the crest amplification effect is related to a focusing of waves below the convex morphologies. The highest value of relative convex/concave amplification $(\approx 3.26)$ is observed for a hill in the left part of Profile 4 $(\mathrm{At}=2.02$ at the crest versus $\mathrm{At}=0.62$ in the valley). This difference is observed over a distance of less than
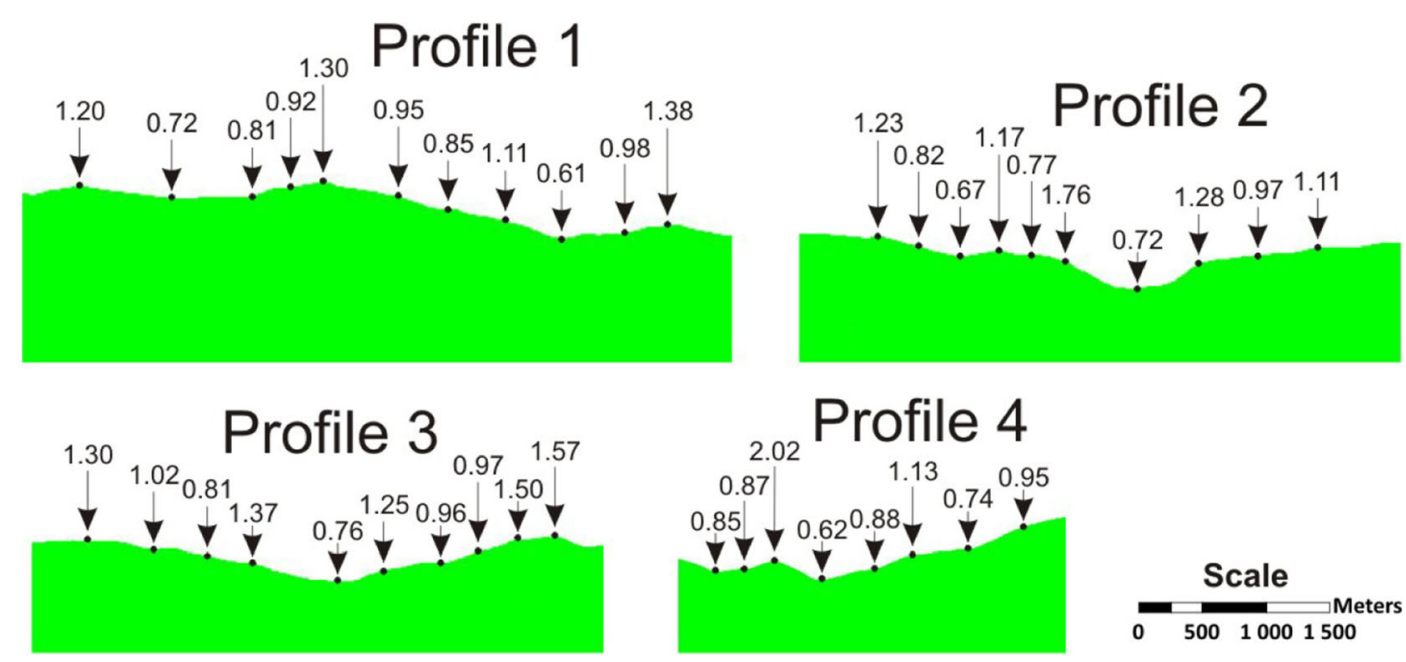

Fig. 6 Distribution of the $A_{t}$ values, observed for four longest profiles (profile 1, 2, 3 and 4). 
$500 \mathrm{~m}$. The resulting distribution indicates that known relationships for the PGA amplification (see, e.g. Geli et al. 1988) could also be applied to Ia:

- wave focusing below convexities results in the amplified values of Ia at the hill crest;

- middle parts of concavities and the toe of a slope are marked by deamplified values of Ia;

- relative crest/toe amplification of Ia values can reach a factor of more than 3 .

\section{Spectral amplification}

To study the spectral amplification patterns we compare the frequency content of surface recordings with the reference one. Figure 7 a presents examples of surface and reference acceleration-time histories for profile 1 (the surface receiver is situated on the crest of the highest hill of profile 1 -see Fig. 6). The spectral amplitude curves for both recordings are presented in Fig. 7b. These curves are produced by the Geopsy software (version 2.7.4) which is commonly applied for signal analysis/processing. The spectral ratio curve, presented in Fig. 7c, is obtained by dividing the surface amplitude spectrum over the reference one. This spectral ratio curve provides a basis for our spectral analysis as it shows deamplified/ amplified spectral ranges and related amplitudes.

Figure 8 presents a set of the spectral ratio curves for profile 3 with vertical exaggeration 1:2.5 to better highlight presented convex/concave features. The results are obtained for a Ricker shape shear stress input signal with the central frequencies of 1.4 and $3.5 \mathrm{~Hz}$. A careful analysis of the spectral ratio curves reveals a recurrent feature related to the position of amplified peaks. First, most amplified peaks are found on top of convex morphologies. For example, a convexity between P3.04t and P3.06t is characterised by the amplified frequency range around 1.8-1.9 Hz (see peak 3 in Fig. 8). The crest of this convexity (P3.05t) has the maximal value of spectral ratio for peak 3. At both toes (P3.04t and P3.06t) lower values of spectral ratio are observed. The same observation can be made for other peaks, e.g. peak 2, 4 and 6 .

The amplified peaks disappear at a certain distance from a given convexity, but some residual amplification is still observed at the neighbouring receivers. For example, while peak 4 is associated with a hill between P3.07t and P3.09t, it is still presented at P3.10t, situated outside of this hill. This residual impact, so-called neighbourhood effect, has already been mentioned by former studies (e.g. Geli et al. 1988).

In total, eight amplified peaks are structurally correlated with convexities of different sizes along profile 3. In all cases, the hill crest has the highest spectral amplification at the amplified frequency range. A position of amplified peaks indicates that low-frequency amplification is related to the large-scale features. For example, peak $1(\approx 0.7 \mathrm{~Hz})$ is related to the entire hill in the left part of the profile with a baseline length of at least $2500 \mathrm{~m}$. This peak 1 is replaced by peak 5 , which is related to the 2000-m long hill in the right part of the profile. Some residual amplification at peak 1 is observed for receiver P3.12t, since the spectral ratio value at peak 5 is more than in other receivers, situated higher in the slope.

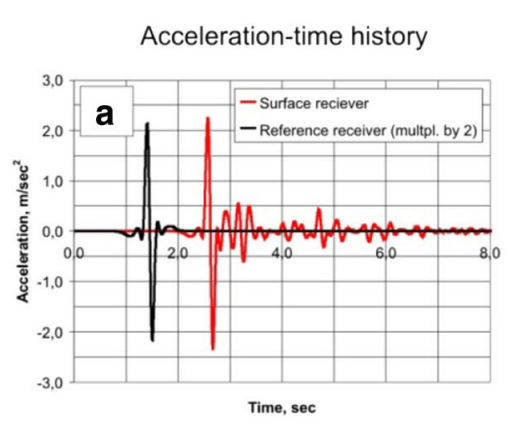

Fig. 7 The examples of a acceleration-time histories, recorded at sample surface receiver (see P1.21 t in Fig. 9) and corresponding reference one (the last one is multiplied by 2 ), $\mathbf{b}$ the smoothed (Konno and Ohmachi, $25 \%$ - Geopsy) spectral amplitude curves,
Spectral amplitide (smoothed - Konno\&Ohmachi, 25\%)

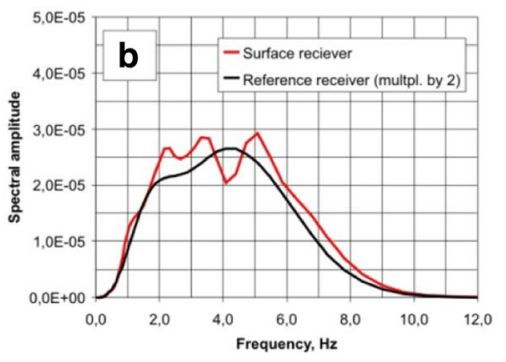

Spectral ratio (smoothed - Konno\&Ohmachi, 25\%)

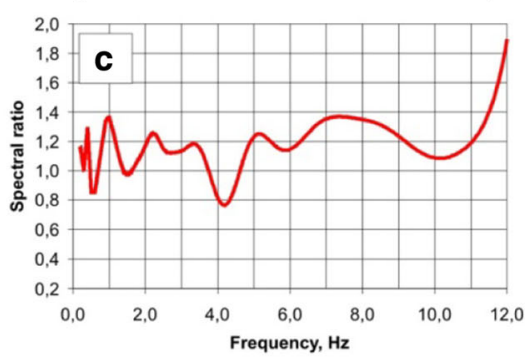

c the smoothed (Konno and Ohmachi, $25 \%$ - Geopsy) spectral ratio curve (for the Ricker shape shear stress signal with the central frequencies of 1.4 and $3.5 \mathrm{~Hz}$ ). 
Profile 3

(vertical exaggeration 1:2.5)
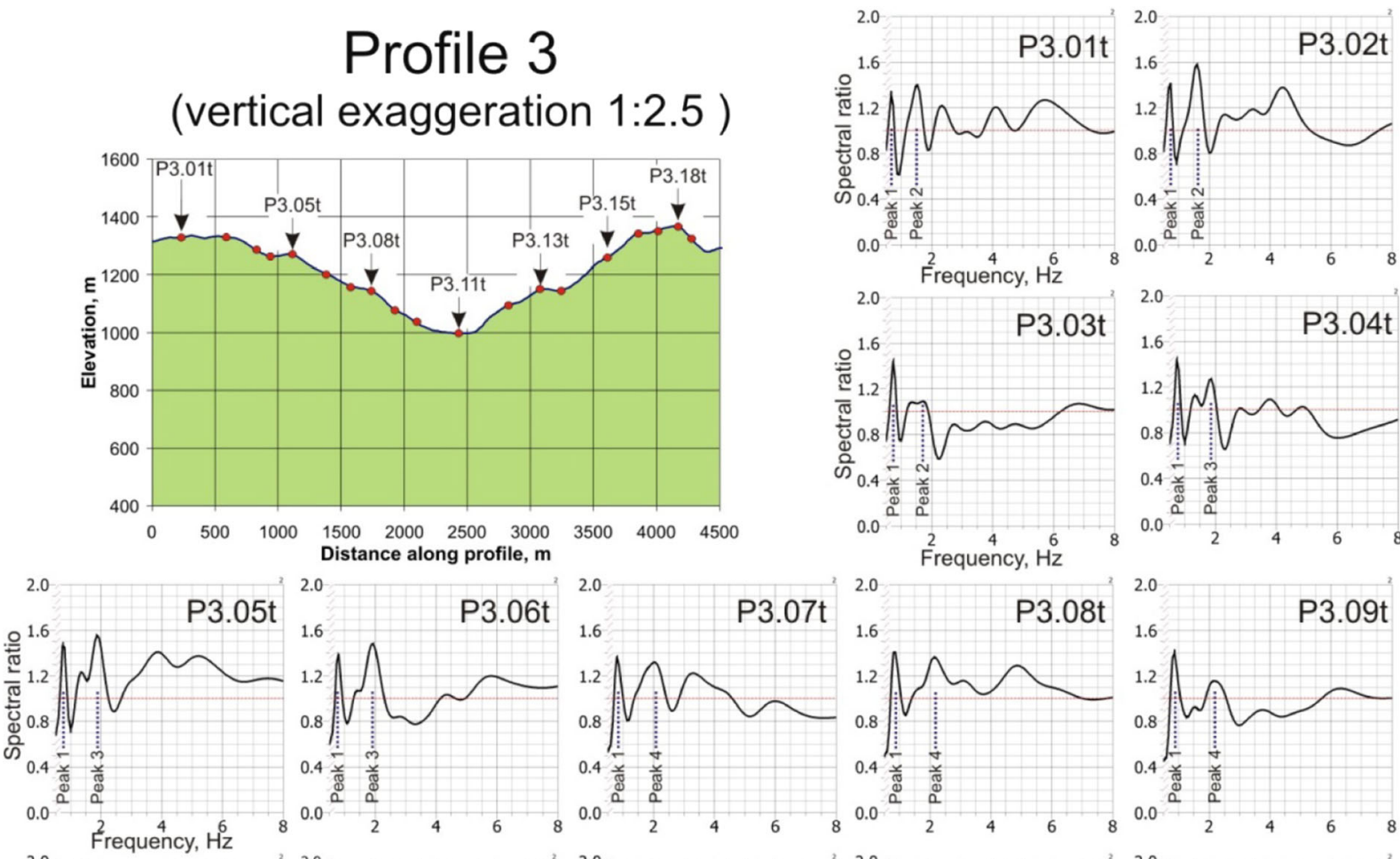

P3.08t
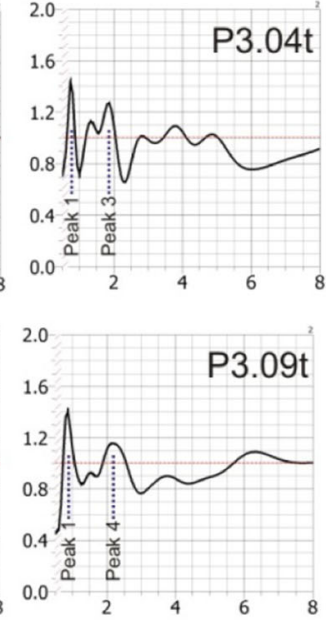

P3.11t
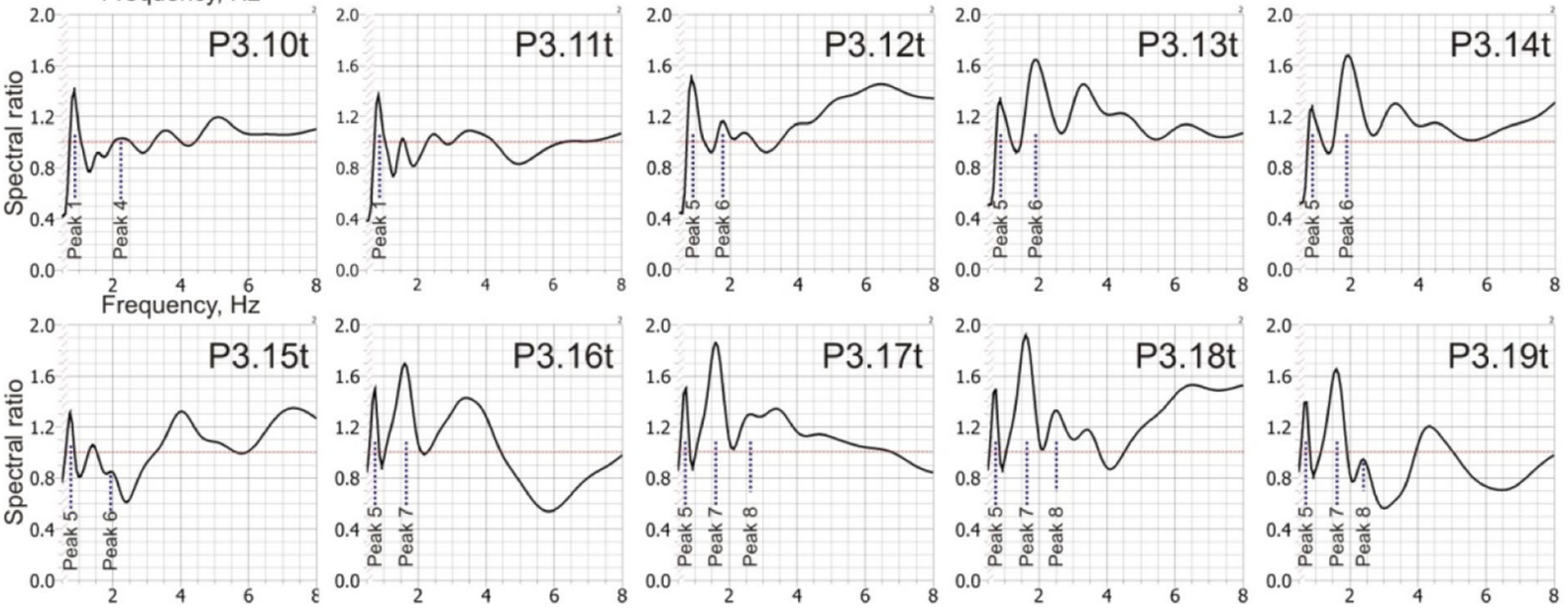

Fig. 8 Results of a spectral analysis for profile 3 represented via the spectral ratio curves for some of the surface receivers (the modelling results are for the Ricker wavelet shear stress input signal with central frequencies of 1.4 and $3.5 \mathrm{~Hz}$ ).

While most of the amplified peaks could be associated to the certain convexities, there are still some with unclear origin. For example, surface receiver P3.05t contains two additional peaks at a higher frequency range (see those at 3.8 and $5.2 \mathrm{~Hz}$ in Fig. 8). Another example is presented by receiver $\mathrm{P} 3.11 \mathrm{t}$, which is situated in the middle of a depression. This receiver has peak 1, which can be explained by the neighbourhood effect. It also has two amplified peaks in the higher frequency range (see the ones at 2.5 and $3.5 \mathrm{~Hz}$ in Fig. 8). These last peaks could hardly be explained, as the central part of the concavity should normally be characterised by the spectral deamplification. The origin of these peaks should be clarified by the additional studies and, therefore, it is the future research target, lying outside of our current objectives.

The results of spectral studies follow the links established by previous research. For example, Geli 
et al. (1988) state that the peak spectral amplification on the mountain top is observed for a wavelength roughly equal to the hill/mountain width, i.e.:

$$
\mathrm{Fa}=\frac{\mathrm{Vs}}{L}
$$

where $\mathrm{Fa}(\mathrm{Hz})$ is the amplified frequency range, $\mathrm{Vs}$ $(\mathrm{m} / \mathrm{sec})$ is the shear-wave velocity (here is $1300 \mathrm{~m} / \mathrm{sec}$ ) and $L(\mathrm{~m})$ is the hill/mountain width, otherwise a length of the convexity baseline.

Ashford et al. (1997) establish a link between a slope height and peak spectral amplification of motion at the crest of a steep slope. They show that this amplification occurs at a normalised frequency $H / \lambda=0.2$, where $H$ is the slope height and $\lambda$ is the wavelength of the motion.

To analyse these relationships, Fig. $9 \mathrm{~b}$, c present the plots of the amplified frequency values versus both hill dimensions (see H and L in Fig. 9a). These plots represent the experimental dataset obtained for all six profiles applying the Ricker shape shear stress input signal with the central frequency of 1.4 and $3.5 \mathrm{~Hz}$. At the same time, a fit between our data and the previously established laws is analysed. Fig. $9 \mathrm{~b}$ demonstrates that the observed distribution is in agreement with the relationship proposed by Geli et al. (1988). It is confirmed by the high value of correlation coefficient $(0.93)$ for a link between our experimental dataset and the Geli's law. An analysis of the hill height shows that a value of the amplified frequency is more related to the square root of the hill height (see the trendline in Fig. 9c), rather than to its original value as it is shown by Ashford et al. (1997). This discrepancy can be explained by the fact that the above-mentioned authors analyse steep slope geometry, which is not our case. Nevertheless, the high value of correlation coefficient $(0.91)$ for the fit between our experimental dataset and the presented trend line shows that the range of the amplified frequency is also impacted by the slope height.

Thus, our spectral studies imply that the amplified frequency range is determined by both $L$ and $H$, rather than by a single hill dimension. Generally, the larger morphologies, i.e. those with higher $L$ and $H$, induce amplification at low frequencies, while smaller morphologies amplify at higher frequencies. Maufroy et al. (2015) apply this link to relate the spectral amplification to the frequency-scaled curvature (FSC) which represents the values of earth's surface curvature doublesmoothed over a specific spatial extent (see a more detailed review of curvature and FSC later in the
"Curvature, FSC and smoothed curvature" section). The size of smoothing extent in FSC laterally expresses the size of analysed morphology. On the other hand, Torgoev et al. (2013c) show that curvature can explain the topographic amplification of Ia values observed in $2 \mathrm{D}$ dynamic tests. These links indicate that Ia amplification should somehow be related to spectral amplification which, in turn, shows a potential to apply FSC in prediction of At. As FSC presents the predictor which can be conveniently mapped in $3 \mathrm{D}$ domain we further analyse related links in more details.

\section{Spectral amplification versus the Ia and At}

To establish a link between the spectral amplification and the value of Ia (and At) we turn to Parseval's theorem (Parseval des Chênes 1806). It states that an integral of the squared function is equal to an integral of the squared Fourier transform of this function. In our case, the acceleration-time history is the function and, according to Eq.(3), the integral of the squared function multiplied by a pre-defined constant is the value of Ia. The Fourier transform of the acceleration-time history is its amplitude spectrum. It denotes that the value of Ia for a given acceleration-time history can be calculated in two ways:

$I_{a}=\frac{\pi}{2 * g} * \int_{0}^{T_{d}}[a(t)] \mathrm{dt}=\frac{\pi}{2 * g} * \int_{0}^{\infty}[S(\phi)] d \phi$

where $a(t)$ is acceleration-time history (with dt as time interval) and $S(\varphi)$ is spectral amplitude curve (with $d \varphi$ as frequency interval).

Introducing Eq.(7) into Eq.(5) the value of At for surface receiver ' $\mathrm{n}$ ' $\left(\mathrm{At}_{\mathrm{n}}\right)$ can be calculated as:

$$
\mathrm{At}_{\mathrm{n}}=\frac{\mathrm{Ia}_{\mathrm{n}}}{\mathrm{Ia}_{\mathrm{o}}}=\frac{\frac{\pi}{2 * g} * \int_{0}^{\infty}\left[S_{\mathrm{n}}(\phi)\right] d \phi}{\frac{\pi}{2 * g} * \int_{0}^{\infty}\left[S_{0 \mathrm{n}}(\phi)\right] d \phi}=\frac{\int_{0}^{\infty}\left[S_{\mathrm{n}}(\phi)\right] d \phi}{\int_{0}^{\infty}\left[S_{0 \mathrm{n}}(\phi)\right] d \phi}
$$

where $S_{\mathrm{n}}(\varphi)$ is the amplitude spectrum for a given surface receiver and $S_{0 \mathrm{n}}(\varphi)$ is the amplitude spectrum for the reference receiver of the corresponding model. 

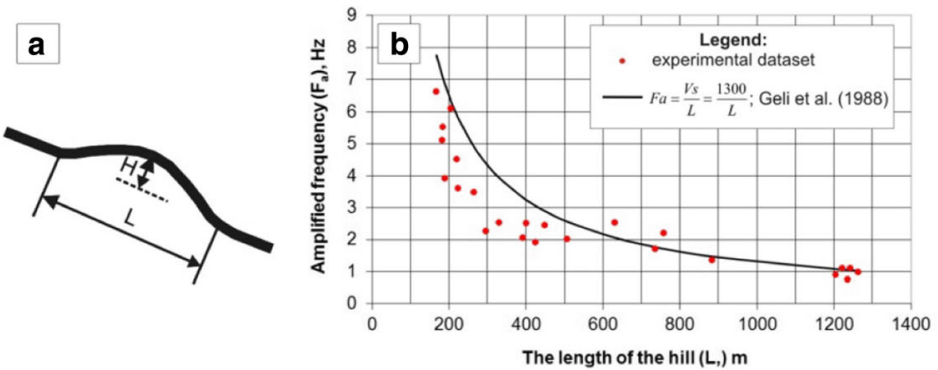

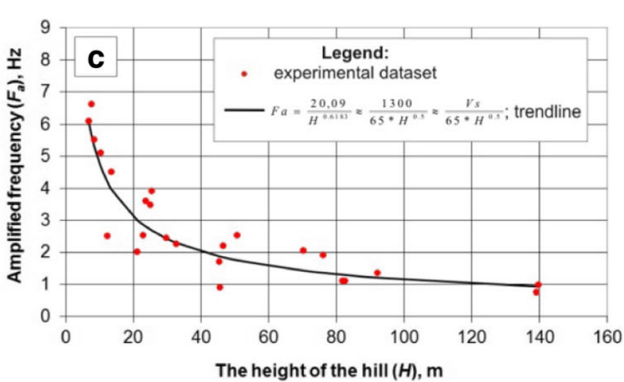

Fig. 9 a Comparison of the experimental dataset versus, b the law, established by Geli et al. (1988) for a link between the amplified frequency value and the length of hill/convexity baseline, $\mathbf{c}$ the trendline with the square root of the hill height.

According to Fig. 7, $S_{\mathrm{n}}(\varphi)$ can be represented by a multiplication of the spectral ratio curve, $R s_{\mathrm{n}}(\varphi)$, and the reference amplitude spectrum, $S_{0 \mathrm{n}}(\varphi)$ :

$S_{\mathrm{n}}(\phi)=R s_{\mathrm{n}}(\phi) * S_{0 \mathrm{n}}(\phi)$

In this case Eq.(8) can be represented as:

$$
\mathrm{At}_{\mathrm{n}}=\frac{\int_{0}^{\infty}\left[S_{\mathrm{n}}(\phi)\right] d \phi}{\int_{0}^{2}\left[S_{0}(\phi)\right] d \phi}=\frac{\int_{0}^{\infty}\left[R S_{\mathrm{n}}(\phi)^{2} S_{0 \mathrm{n}}(\phi)\right] d \phi}{\int_{0}^{\infty}\left[S_{0 \mathrm{n}}(\phi)\right] d \phi}
$$

This last equation shows that the value of At depends on two factors: the spectral ratio curve for a given surface receiver and the amplitude spectrum for the input acceleration-time history. Figure 10 analyses how these factors, i.e. $R s_{\mathrm{n}}(\varphi)$ and $S_{0 \mathrm{n}}(\varphi)$, impact the final values of Ia and At. It is presented for the example of a surface receiver (see P3.01 t in Fig. 8) subjected to two Ricker shape shear stress input signals with varying frequency content. The high-frequency signal has the central frequency values of 1.4 and $3.5 \mathrm{~Hz}$ (Fig. 11a), while the low-frequency signal has the values of 1.0 and $2.0 \mathrm{~Hz}$ (Fig. 11b).

According to Eq.(7) and (8), the values of $\mathrm{Ia}_{1} \mathrm{Ia}_{0}$ and At for both cases are calculated via the surface and reference spectral amplitude curves. While the surface amplitude spectrum is different for both tests, there is some consistency revealed. Both curves have the unique amplified peaks (see peaks 1, 2, 3, 4 and 5 for blue and red curves in Fig. 10a, b), while the spectral amplitude values at these peaks are different (compare the values in the same Fig. 10a, b).

Meanwhile, the shape of the spectral ratio curve is almost identical for the two modelling cases (compare the ones in Fig. 10c). A significant difference at the frequency range more than $5.0 \mathrm{~Hz}$ is artificial. It is related to the fact that there is a negligible portion of energy presented in the low-frequency signal after $5.0 \mathrm{~Hz}$ - it provides artificially low values of spectral ratio at this frequency range. A fit of the spectral ratio curves suggests that, ideally, their shape depends only on the morphological and geotechnical site settings, i.e. Vs, slope height and length, concavity/convexity. In other words, the spectral ratio curve shows deamplification/amplification potential of a given site.

The input amplitude spectrum (see black dotted lines in Fig. 10a and b) is a site-independent factor and it determines the spectral ranges, where the site amplification potential will most affect the final value of At. Indeed, the Ia value in the case of the high-frequency signal is more impacted by peaks $2,3,4$ and 5 . The lowfrequency signal is more affected by peaks 2 and 3 with a smaller input from peak 4 . It can also be seen, that peak 5 has an almost negligible input into the Ia value of the low-frequency signal, while both modelling cases are much less impacted by peak 1 . The observed difference in the spectral amplitude distribution results in the varying values of Ia and At for both cases. The highfrequency signal is more amplified in terms of the Ia values $(A t=1.23$ versus $A t=1.15)$.

The same consistency is revealed for the sinusoidshape signals, tested on the same receiver (see the results in Fig. 11). It can be seen that the $5.0 \mathrm{~Hz}$ input signal has the highest value of $A t=1.20$, since its central frequency coincides with two amplified peaks, namely peak 4 at $4.1 \mathrm{~Hz}$ and peak 5 at $5.6 \mathrm{~Hz}$ (see Fig. 11c). The $2.0 \mathrm{~Hz}$ signal is also strongly impacted by two amplified peaks (peaks 2 and 3), but it has lower value of At (see Fig. 11a). This difference of the At values is explained by very broad amplification provided by peak 5 in the neighbouring spectral range (see Fig. 11d), while the 
Ricker shape shear stress wave $(1.4$ and $3.5 \mathrm{~Hz})$

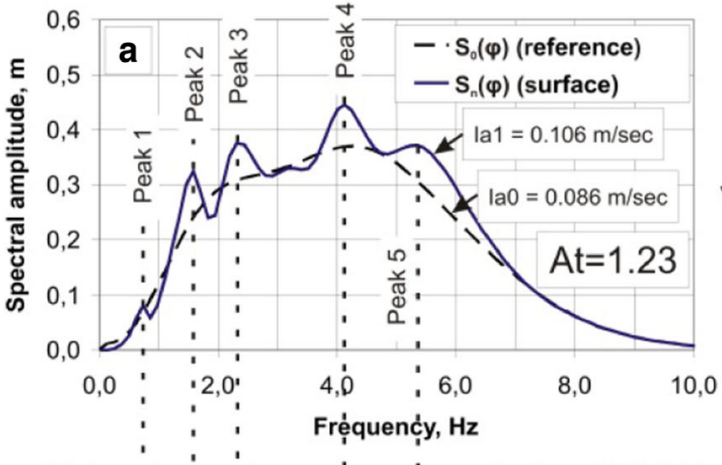

Ricker shape shear stress wave $(1.0$ and $2.0 \mathrm{~Hz})$

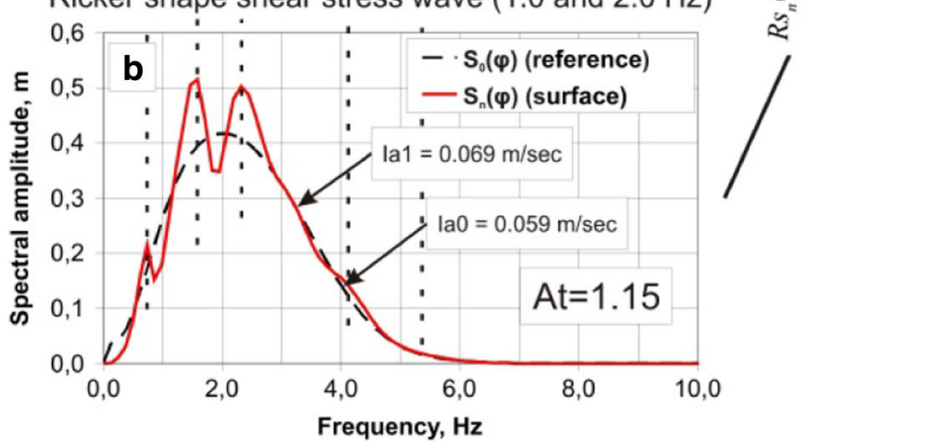

$\mathrm{RS}_{\mathrm{n}}(\varphi)$ - spectral ratio curves

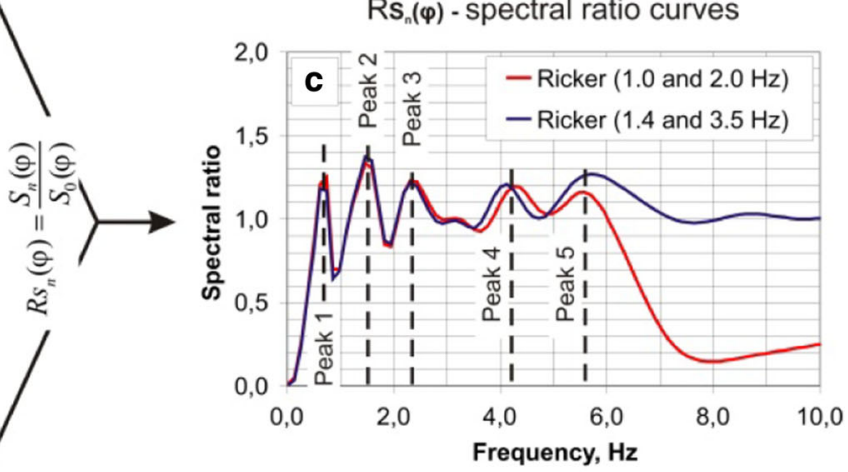

Fig. 10 The spectral amplitude and spectral ratio curves (c) obtained for a sample surface receiver (see P3.01t in Fig. 8) subjected to high $\mathbf{a}$ and low $\mathbf{b}$ frequency Ricker shape shear stress waves

with indication of $\mathrm{Ia} 0$ and Ia 1 values (respectively, for input and amplified signal) as well as corresponding At values.

range between peaks 2 and 3 is even deamplified (see the range of $1.9 \mathrm{~Hz}$ in Fig. 11a). The $3.5 \mathrm{~Hz}$ signal has the lowest At value (1.06), which is strongly related to the spectral deamplification at the range of $2.7-3.8 \mathrm{~Hz}$ (see this range in Fig. 11b). All modelling cases have an almost identical shape of the spectral ratio curves (see Fig. 11d), which is also similar to the ones of the Ricker shape input signals (compare Fig. 10c and Fig. 11d). It confirms that, ideally, the spectral ratio curve depends only on the site settings and is independent from the input signal.

Thus, our studies reveal an explicit link between At and the spectral amplification. Should the central frequency of the input signal coincide with the amplified frequency range, it will also result in amplification of the Ia value $(A t>1)$. Similarly, if a certain site is characterised by spectral deamplification at the central frequency of the input acceleration- time history, it will also result in the deamplified value of Ia for this signal $($ At $<1)$. The other spectral ranges can also impact the final value of At. This impact is more pronounced for the signals with broad input spectrum, as amplification of lateral frequencies starts to play a role. Reversely, the narrow input spectrum results in close link between At and spectral amplification near the central frequency range.
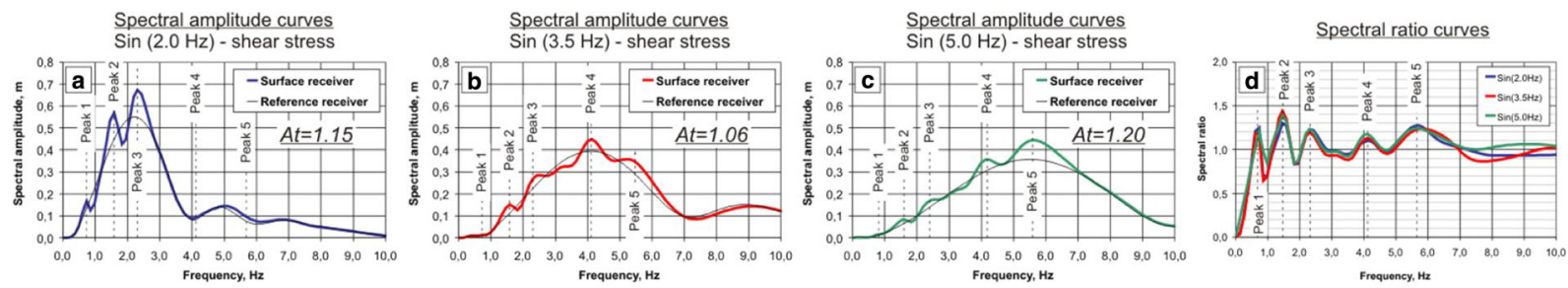

Fig. 11 The spectral amplitude (a-c) and the spectral ratio (d ) curves obtained for a sample surface receiver (see P3.01t in Fig. 8) subjected to sinusoid-shape shear stress waves with varying frequency content. 
The link between At and spectral amplification shows the potential to predict the Ia amplification based on FSC. This last parameter presents the surface curvature which is double-smoothed over the extent predicted by Geli's law. The potential to predict the value of At based on the curvature is also indicated by Torgoev et al. (2013c), even though the authors do not apply any smoothing and analyse the original curvature values. In addition, the authors did not test the signals with changing central frequency, while its impact on At is proved by us here. Therefore, we further use signals of varying shape and changing central frequency to analyse how the amplification of Ia value can be predicted by curvature.

\section{Curvature, FSC and smoothed curvature}

The basic concept of curvature as the topographic index is reviewed by Evans (1979) and Zeverbergen and Thorne (1987). The authors analyse a part of DEM represented by a moving window with dimensions of $3 \times 3$ cells where the cell values denote elevation (see schematic view in Fig. 12a). The presented distribution of nine elevation values is further fit by the polynomial functional surface (see the one in Fig. 12a). The 1st spatial derivative of this polynomial function, i.e. change of elevation per unit of spatial extent, is defined as the slope. The 2 nd spatial derivative of the same polynomial function is the curvature and it shows a change of slope per unit of spatial extent. The authors further define two basic directions along which curvature can be calculated, i.e. along the direction of maximum slope (profile curvature) and transversely to it (planform curvature). Moore et al. (1991) incorporate both types of curvature to get the parameter termed as the general curvature. Fig. 12a shows a technique adopted by the ArcGIS code to calculate the value of general curvature in $3 \mathrm{D}$ domain. Here, $D$ and $E$ reflect curvature in both orthogonal directions and general curvature is calculated for the central cell marked as $Z 5$. The positive value of general curvature shows upward convexity, while negative value represents downward concavity.

Figure 12b shows how the concept of general curvature is adapted to the $2 \mathrm{D}$ domain. In this case, the curvature is calculated along a single direction, i.e. along the model surface. As the 2D cross-section normally shows the direction of the maximum slope, the value of $D$ in this case is equal to 0 . That way the $3 \mathrm{D}$ general curvature transforms into a parameter termed either as $2 \mathrm{D}$ general or $2 \mathrm{D}$ profile curvature. This concept of curvature calculation is applied to analyse our data. The choice is driven by the fact that 2D and 3D curvatures in this concept are clearly linked, which should further assist in the comparison of data. In this case the curvature baseline length, referred as $L$ in Fig. 12b, corresponds to twice of a DEM pixel size in Fig. 12a, i.e. $L=2 \mathrm{~L}_{\mathrm{p}}$. As the surface of our models is sampled every $21 \mathrm{~m}$, the minor baseline to which the value of curvature can be calculated corresponds to $L=2 \mathrm{~L}_{\mathrm{p}}=42 \mathrm{~m}$. For further convenience those elementary curvature values, i.e. calculated for $L=42 \mathrm{~m}$, are referred as Curv.

The next critical issue is related to the smoothing of curvature values. In applied meaning the smoothing expresses the procedure which returns the mean value of curvature over a given spatial neighbourhood which is determined by the smoothing length. We suppose that the smoothing of curvature values can be performed via two main options: the direct smoothing of the elementary curvature values or extraction of curvature based on the smoothed elevation data. The last option implies that, first, the elevation values should be smoothed and, then, the curvature is calculated. Moreover, the smoothing itself can be applied several times. For example, Maufroy et al. (2015) apply double-smoothing of original curvature values to get the parameter termed as FSC. In this respect, given the variety of smoothing options, we prefer to treat FSC as the particular case of smoothed curvature.

In this study, we do not compare At values with the FSC, as we focus on simple prediction techniques. Figure 13a demonstrates a sample distribution of the curvature values (Curv) near the $\mathrm{P} 4.05 \mathrm{t}$ receiver (profile 4). These curvature values are calculated for every surface node according to Fig. 12b: Z11 is the elevation at the studied node, while $\mathrm{Z} 10$ and $\mathrm{Z} 12$ are the neighbouring elevation values. Figure $13 \mathrm{~b}$ shows how this distribution of Curv values is applied to calculate the smoothed curvature for the same surface receiver, i.e. for P4.05t. As it can be seen, the applied algorithm collects all Curv values within a specific neighbourhood from P4.05t and returns the mean value. For example, $\mathrm{Curv}_{84}$ represents the mean curvature over the neighbourhood of $84 \mathrm{~m}$, while $\operatorname{Curv}_{126}$ is calculated by averaging all Curv values over the neighbourhood of $126 \mathrm{~m}$ (see the smoothing neighbourhood in Fig. 13a 


\section{D curvature}

a

2D curvature

b

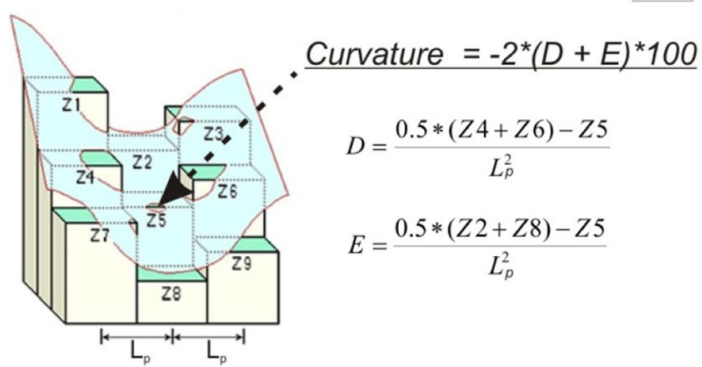

Fig. 12 a Calculation of general curvature in 3D domain based on elevation data from DEM, where $Z 1, Z 2 \ldots Z 9$ are the elevation values for the corresponding pixels $(\mathrm{m})$ and $L_{\mathrm{p}}(\mathrm{m})$ is DEM pixel

and sample calculations in Fig. 13b). According to this approach the smoothed curvature values with $\mathrm{L}$ ranging from $84 \mathrm{~m}$ till $798 \mathrm{~m}$ are calculated for all surface receivers of six studied models. These smoothed curvature values are further analysed regarding their relationship with observed amplification of Ia.

\section{At versus smoothed curvature}

To study the link between At and the smoothed curvature we first plot both parameters versus each other. Figure 14 presents the results of the tests with the Ricker shape input signal $(1.4$ and $3.5 \mathrm{~Hz})$ where the data from all six models are included. The presented graphs plot the At values versus both smoothed and original curvature (see the graph for $L=42 \mathrm{~m}$ ). The smoothed curvature values result from a smoothing over $\mathrm{L}$ ranging from $84 \mathrm{~m}$ up to $798 \mathrm{~m}$.

The plots demonstrate that distribution of linear correlation values follows a certain rule (see this value at the bottom of each graph). Starting from $L=42 \mathrm{~m}$ these values are growing, reaching the maximum at $L=294 \mathrm{~m}$ (see a graph marked by a dotted rectangle in Fig. 14). At

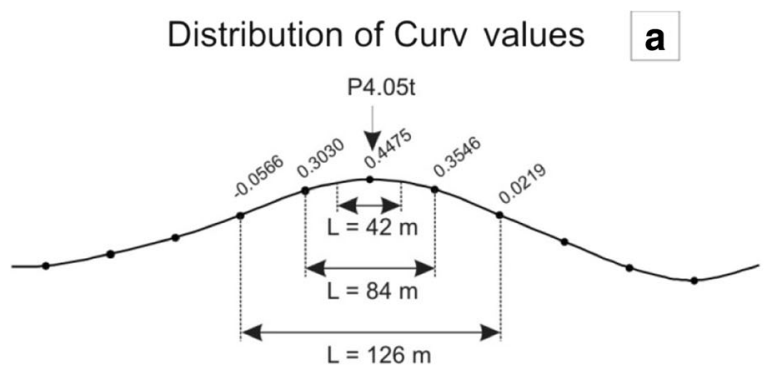

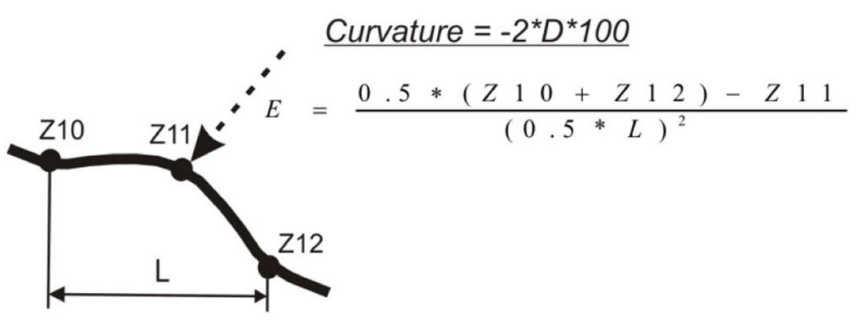

size (ESRI 2012 modified). b Calculation of general curvature in 2D domain, where Z10, Z11 and Z12 are the elevation values (m) and $L(\mathrm{~m})$ is a curvature baseline length (note: $L=2 L_{\mathrm{p}}$ ).

the values of $L$ more than $294 \mathrm{~m}$, the correlation values are again decreasing. It suggests that the distribution of At for the studied input signal is best linearly predicted by a curvature with $L=294 \mathrm{~m}$, i.e. by $\operatorname{Curv}_{294}$. This specific value of $L$ is further referred to as effective smoothing length (Le), while the corresponding curvature is termed as effective curvature ( $\left.\mathrm{Curv}_{\mathrm{Le}}\right)$.

The correlation between At and smoothed curvature is also analysed for other tested signals. Figure 15 presents the curves which show how the change of $\mathrm{L}$ impacts the linear correlation between both parameters. The Ricker signal analysed in Fig. 14, is presented by a blue dotted line in Fig. 15a (see Le=294 m). The other signals are only tested on profile 3 . They include the low-frequency Ricker (red curve in Fig. 15a) and the sinusoid-shape signals with different values of central frequency (Fig. 15b).

The analysis of curves shows an agreement with the graphs shown in Fig. 14. All curves contain some peak value of correlation coefficient which is attributed to the effective smoothing length, i.e. Le. To both sides from Le the correlation coefficients gradually decrease. The value of Le is inversely related to the central frequency. The sinusoid-shape signals soundly confirm that link:

Fig. 13 a 2D distribution of the Curv values around sample surface receiver ( $\mathrm{P} 4.05 \mathrm{t}$ from profile 4$)$. b The calculation of the smoothed curvature values for $L=84 \mathrm{~m}$ and $L=126 \mathrm{~m}$. 

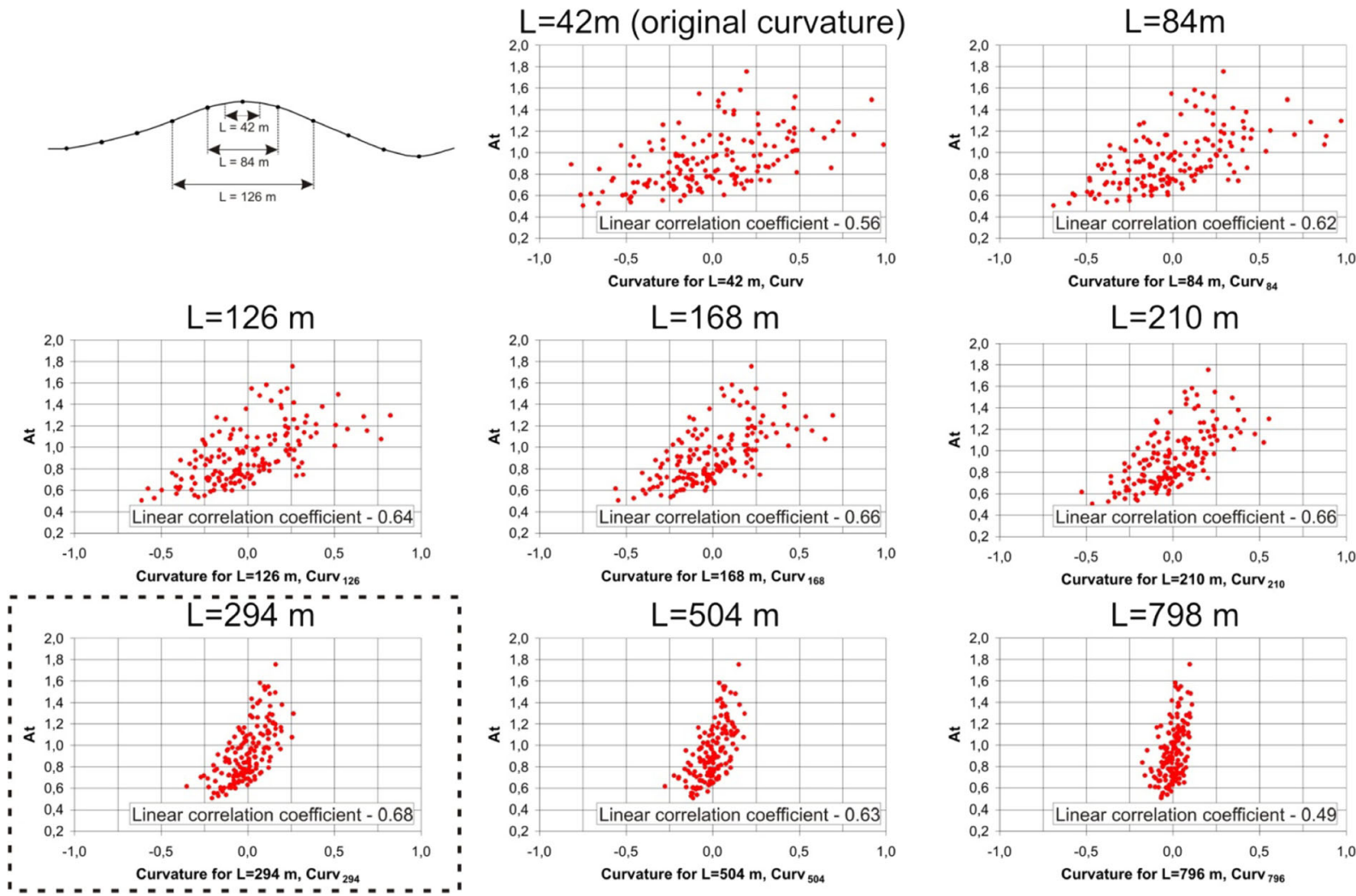

$\mathrm{L}=798 \mathrm{~m}$

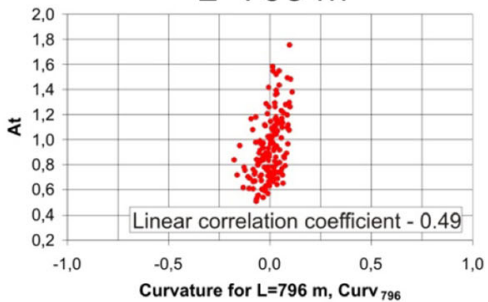

Fig. 14 Plots of $A_{t}$ values versus smoothed curvature for the dynamical simulations applying the Ricker shape input signal (shear stress) with the central frequencies 1.4 and $3.5 \mathrm{~Hz}$ (the best correlation is marked by a dotted rectangle).

Sin $(2.0 \mathrm{~Hz})$ signal has $\mathrm{Le}=504 \mathrm{~m}$, Sin $(3.5 \mathrm{~Hz})$ signal has $\mathrm{Le}=336 \mathrm{~m}$, Sin $(5.0 \mathrm{~Hz})$ signal has $\mathrm{Le}=168 \mathrm{~m}$ and $\operatorname{Sin}(6.0 \mathrm{~Hz})$ has Le $=126 \mathrm{~m}$ (see Fig. 15b).

Some curves shown in Fig. 15 are asymmetric. For example, the one for the low-frequency Ricker signal (red curve in Fig. 15a) is more inclined in a part with
$L<$ Le. The input spectrum shown in Fig. 10b explains this asymmetry: the comparatively narrow input spectrum, ranging from 0.0 up $6.0 \mathrm{~Hz}$, results in a lower impact of the curvature with smaller $L$, while the curvature with larger $L$ affects the value of At more. The highfrequency Ricker signal has a more symmetric shape
Ricker shape input signal

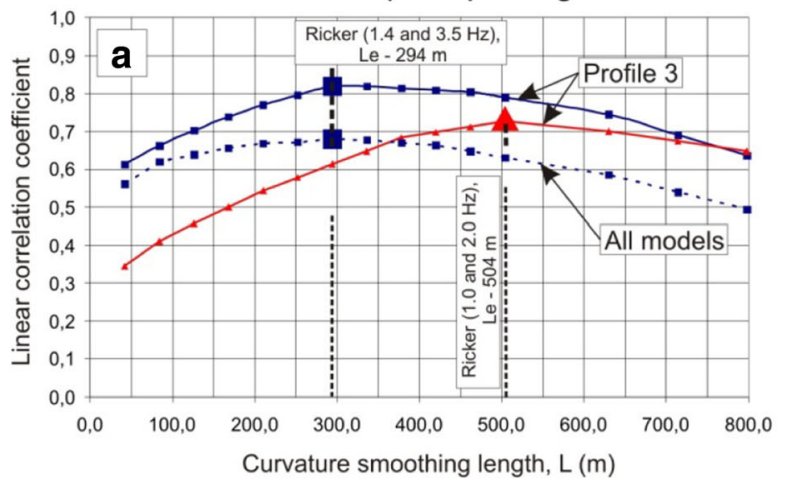

Sinusoid shape input signal (Profile 3)

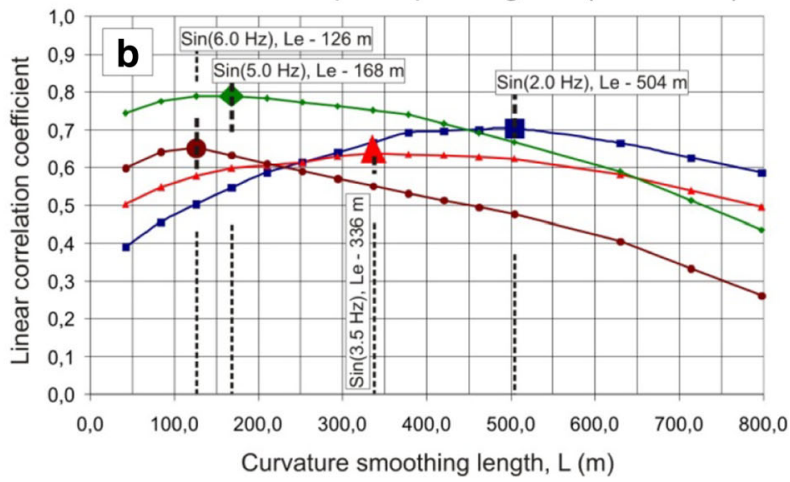

Fig. 15 A distribution of the linear correlation coefficients for a link between At and the curvature with varying smoothing length: a for the tests with Ricker shape shear stress input signals, b. for the tests with the sinusoid-shape shear stress input signals (only profile 3 ). 
(see the blue lines in Fig. 15a). Figure 10a shows that this signal has a much broader input spectrum; therefore, the At values for this signal are almost equally impacted by curvature with both small and large values of $L$.

The observed link between Le and central frequency of input signal is further studied in Fig. 16 (red dotsRicker signals, blue dots-sinusoid signals). Here, we analyse the central frequency of the input accelerationtime history $\left(F_{\mathrm{ca}}\right)$, which is derived from the input spectrum constructed in the Geopsy software (see, e.g. Fig. 5 for Ricker signals). The values of $F_{\mathrm{ca}}$ are higher than those for the input shear stress. For example, the $2.0 \mathrm{~Hz}$ shear stress corresponds to $F_{\mathrm{ca}}=2.2 \mathrm{~Hz}$ (point 1 ), while the $6.0 \mathrm{~Hz}$ shear stress already corresponds to $F_{\text {ca }}=8.4 \mathrm{~Hz}$ (point 4). The presented distribution is also compared to Geli's law (see the trendline in Fig. 16). It can be seen, that empirical values of Le are highly correlated to the calculated ones (correlation coefficient - 0.88). This fit is very critical as it suggests that Le can be derived from the shear-wave velocity and the central frequency of the input acceleration-time history.

Figure 17 further analyses a link between At and smoothed curvature for four sinusoid-shape signals, tested on profile 3 (40 surface receivers). The graphs also contain linear shape trends together with prediction laws for them. The linear correlation coefficients for these laws correspond to the peak values observed for the same signals in Fig. 15b. As it can be seen, the worst predictions of the At values are performed for the $F_{\text {ca }}=8.43 \mathrm{~Hz}$ signal (linear correlation coefficient of around 0.64$)$. Slightly better predictions are performed for the $F_{\mathrm{ca}}=2.22 \mathrm{~Hz}$ and $F_{\mathrm{ca}}=5.65 \mathrm{~Hz}$ signals, as the corresponding coefficients are equal to 0.68 and 0.67 . The best predictions are obtained for the $F_{\mathrm{ca}}=3.8 \mathrm{~Hz}$ signal, as the correlation coefficient equals to 0.78 . The variation of correlation values seems to be nonsystematic and not related to $F_{\text {ca }}$. That discrepancy between observed and predicted data is explained above: the At values are not solely influenced by the effective curvature, as some lateral impacts come from the curvature smoothed over other values of $\mathrm{L}$.

An analysis of prediction laws in Fig. 17 reveals some regularity. First of all, the inclination of trends becomes flatter with an increasing value of $F_{\text {ca }}$ (compare the slope coefficients). Second, all equations have an intercept equal to 1, i.e. for $\operatorname{Curv}_{\mathrm{Le}}=0$ the value of At is exactly equal to 1 , which shows a lack of any deamplification/amplification of Ia value. These regularities led to the definition of the general shape of prediction law which can be presented next:

$\mathrm{At}=K^{*} \operatorname{Curv}_{\mathrm{Le}}+1$

where $K$ is a frequency-dependent slope constant.

These four values of $K$ for sinusoid signals are further compared to $F_{\mathrm{ca}}$ to get the relationship between these parameters. The analysis shows that $K$ is best predicted by the next equation:

$K=\frac{2.1770}{F_{\text {ca }}^{0.3905}}$

Introducing Eq.(12) into Eq.(11) we would get the next form of At prediction law (for the sinusoid-shape signals):

$\mathrm{At}=\frac{2.1770 * \operatorname{Curv}_{\mathrm{Le}}}{F_{\mathrm{ca}}^{0.3905}}+1$

The analysis of data from Ricker tests confirmed that the distribution of At can be predicted according to the general law shown in Eq.(11). Nevertheless, some difference is observed. For example, a sinusoid signal with $F_{\text {ca }}=2.22 \mathrm{~Hz}$ has the $K$ value of 1.6246 , while lowfrequency Ricker signal with a comparable $F_{\text {ca }}$ $(2.01 \mathrm{~Hz})$ has the $K$ value of 1.9939 . This difference of around $18-20 \%$ shows that the value of $K$ does not only depend on $F_{\text {ca }}$ but also on the shape of the input spectrum. It shows that prediction of the Ia amplification based on effective curvature should not only consider the central frequency of input spectrum, but also account for its shape.

\section{Conclusions and outlook}

This paper addresses the issues related to the pure topographic amplification of the Arias Intensity (Ia, m/sec) which is important parameter used in the regional Newmark method. This method maps the earthquakeinduced landslide susceptibility via the calculated values of the co-seismic slope displacement. The values of Ia in this method are mapped through empirical attenuation laws which apply a set of regional predictors, most commonly epicentral distance and earthquake magnitude. These laws do not account for the topographic amplification which negatively affects the reliability of final predictions. 
Fig. 16 A plot of the effective curvature baseline length $\left(L_{\mathrm{e}}\right)$ versus the central frequency values for the input acceleration-time history $\left(F_{\text {ca }}\right)$ and a comparison with the law of Geli et al. (1988).

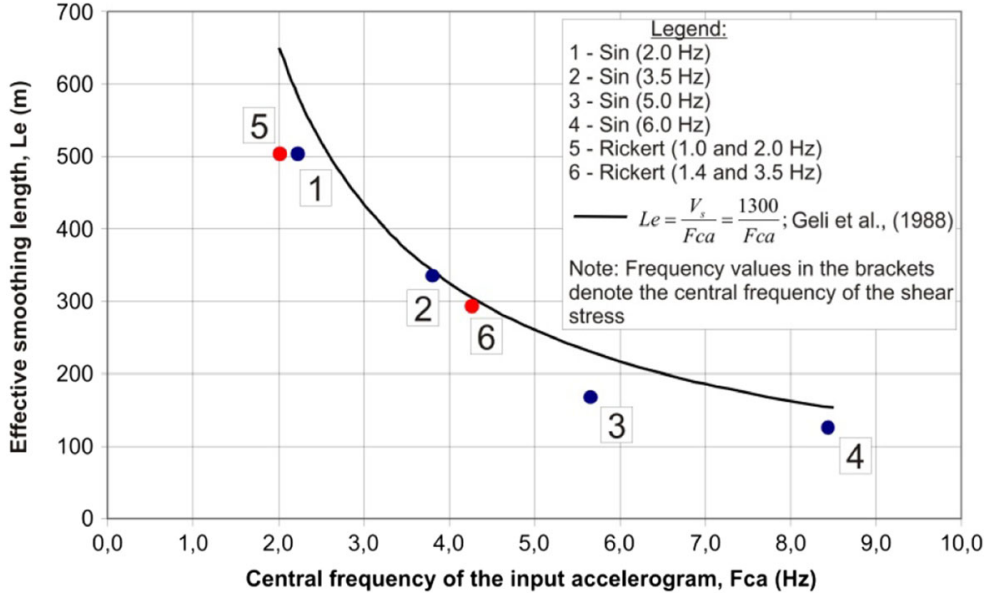

The main goal of our paper is to investigate a potential to include these topographic inputs into the conventional mapping practice. To accomplish this task we analyse $2 \mathrm{D}$ modelling data from six models with total length of about $23.0 \mathrm{~km}$. The models reconstruct the landslide-prone slopes in the Mailuu-Suu River Valley, Southern Kyrgyzstan. The recorded acceleration-time histories are applied to calculate the values of Ia which

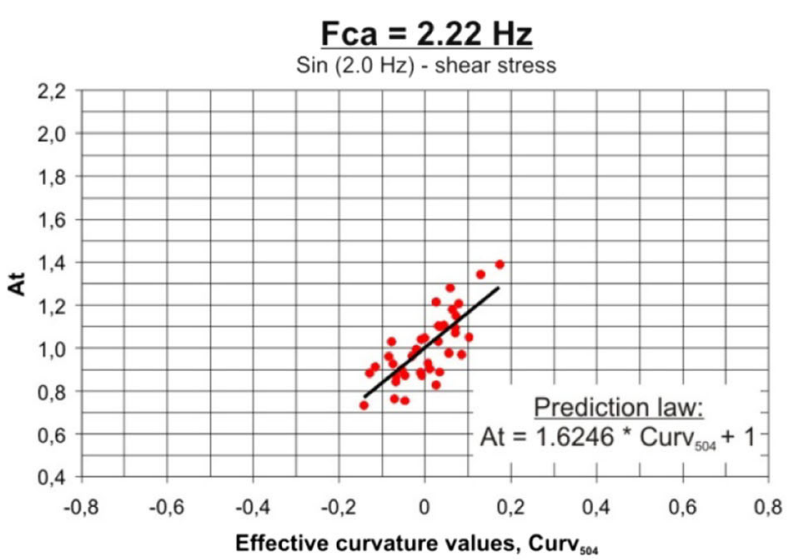

Fca $=5.65 \mathrm{~Hz}$

$\operatorname{Sin}(5.0 \mathrm{~Hz})$ - shear stress

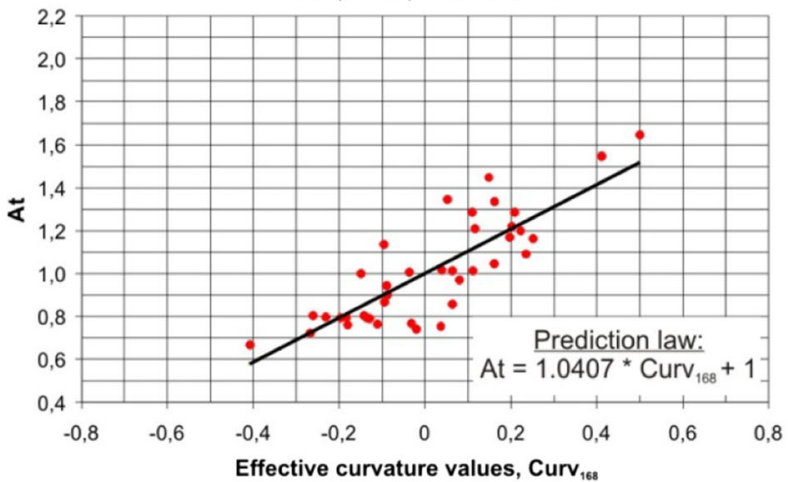

Fca $=3.80 \mathrm{~Hz}$

$\operatorname{Sin}(3.5 \mathrm{~Hz})$ - shear stress

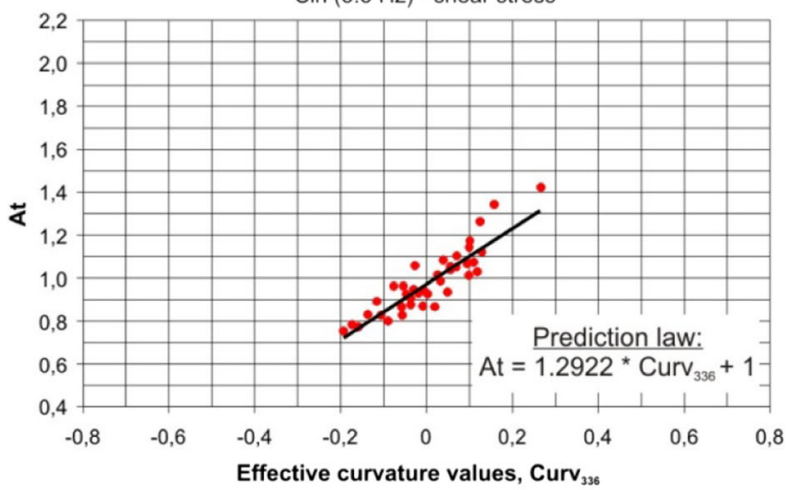

Fca $=8.43 \mathrm{~Hz}$

$\operatorname{Sin}(6.0 \mathrm{~Hz})$ - shear stress

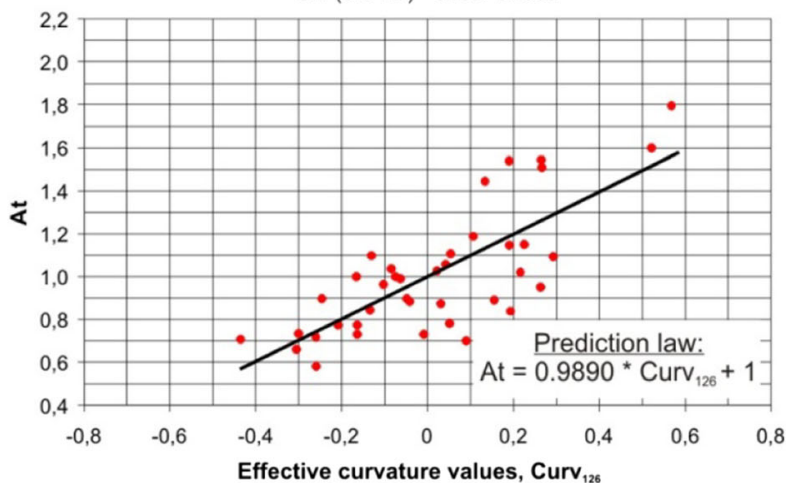

Fig. 17 The plots of the At values versus the effective curvature observed for profile 3 (40 surface receivers) applying sinusoid-shape signals with varying frequency content. 
are further analysed in respect to their link with spectral amplification and surface morphology, expressed via smoothed curvature.

The spectral studies show that Ia amplification (expressed via At) and spectral amplification are directly linked processes. This link is more expressed for the signals with narrow input spectrum when the amplification of central frequency is very crucial. Reversely, this link is less pronounced for the signals with broader input spectrum, as amplification of lateral ranges starts to play bigger role. The spectral studies also confirm that amplified frequency range is related to the size of convex morphology. The larger hills/mountains induce amplification at the low-frequency range, while minor features do it in the high-frequency domain. This link is applied in a well-established FSC proxy where curvature smoothing indirectly expresses the size of morphology playing important role in spectral amplification.

To calculate smoothed curvature in our studies we perform single smoothing over spatial extent called smoothing length $(L)$. Thus, the smoothed curvature represents the mean curvature within spatial extent equal to $L$. The link between At and smoothed curvature of different $\mathrm{L}$ is tracked for input signals with variable spectral content $\left(F_{\mathrm{ca}}\right)$. The analyses show that At values for all tested signals are best predicted on the basis of the so-called effective curvature which is smoothed over effective smoothing length (Le). The value of Le is predicted via $F_{\mathrm{ca}}$ and Vs according to Geli's law. The general form of At prediction law is proposed based on analyses of sinusoid signals. In this law the value of At is related to two main factors: effective curvature and $F_{\text {ca. }}$. This prediction law is also valid for the Ricker signals, while coefficients involved in final equations are different. It shows that the At values are related to both characteristics of input signal: $F_{\mathrm{ca}}$ and entire shape of the input spectrum.

Proposed equations cannot be directly implemented in the conventional Ia attenuation laws which work in the 3D domain. Nevertheless, some 3D morphologies can be approximated by 2D structures. For example, the long ridge has curvature variation only across it, while the curvature along the ridge is equal to 0 . In this specific case, the Ia values should generally be amplified in only one direction and proposed equations can be applied to predict this amplification. However, most morphologies have different shapes which can even be almost symmetric in the 3D domain. It that case the values of Ia are amplified in both orthogonal directions and curvature should account for the 3D shape. It finally implies that development of mapping proxy should be based on $3 \mathrm{D}$ studies. These studies should test the signals with varying shape of input spectrum and changing values of central frequency. The Ia values amplified in both horizontal directions should further be compared versus the curvature smoothed in $3 \mathrm{D}$. In respect to that the different smoothing techniques should also be tested, as they can potentially impact the reliability of final predictions. This set of dynamic analyses would finally let to incorporate the topographic inputs into the conventional mapping practice.

\section{References}

Abdrakhmatov K, Havenith HB, Delvaux D, Jongmans D, Trefois P (2003) Probabilistic PGA and arias intensity maps of Kyrgyzstan (Central Asia). J Seismol 7:203-220

Alioshin Y, Torgoev I (2000). Radioactive ecology of Mailuu-Suu. Bishkek, Ilim.

Ambraseys NN, Menu JM (1988) Earthquake induced displacements. Earthq Eng Struct Dyn 16(7):985-1006

Ambraseys NN, Srbulov M (1995) Earthquake induced displacements of slopes. Soil Dyn Earthq Eng 14:59-71

Arias A (1970) A measure of earthquake intensity. In: Hansen RJ (ed) Seismic design for nuclear power plants. MIT Press, Cambridge, Massachusetts, pp 438-483

Ashford SA, Sitar N, Lysmer J, Deng N (1997) Topographic effects on the seismic response of steep slopes. Bull Seismol Soc Am 87:701-709

Bray JD, Travasarou T (2007) Simplified procedure for estimating earthquake-induced deviatoric slope displacements. J Geotech Geoenviron 133:381-392

Chousianitis K, Del Gaudio V, Kalogeras I, Ganas A (2014) Predictive model of Arias intensity and Newmark displacement for regional scale evaluation of earthquake-induced landslide hazard in Greece. Soil Dyn Earthq Eng 65:11-29

Crespellani T, Madiai C, Maugeri M (1996) Analisi di stabilita di un pendio in condizioni sismiche e post-simiche. Rivista Italiana Geotechnica 1:50-61

de Marneffe C (2010) Cartography and 3D geological modeling of the Mailuu-Suu River Valley. University of Liege, Belgium, Master theses

Del Gaudio V, Wasowski J (2011) Advances and problems in understanding the seismic response of potentially unstable slopes. Eng Geol 122:73-83

Densmore AL, Hovious N (2000) Topographic fingerprints of bedrock landslides. Geology 28:371-374

ESRI (2012) ArcGIS Help Library. www.help.arcgis.com.

Evans IS (1979) An integrated system of terrain analysis and slope mapping. Final report on grant DA-ERO-591-73-G0040. University of Durham, England

Geli L, Bard P, Jullien B (1988) The effect of topography on earthquake ground motion, a review and new results. Bull Seismol Soc Am 78(1):42-62 
Giardini D, Grunthal G, Shedlock KM, Zhang P (1999) The GSHAP - Global Seismic Hazard Map. Ann Geofis 42(6): $1225-1230$

Gorum T, Fan XM, van Westen CJ, Huang RQ, Xu Q, Tang C, Wang GH (2011) Distribution pattern of earthquake-induced landslides triggered by the 12 May 2008 Wenchuan earthquake. Geomorphology 133(3):152-167

Harp EL, Jibson RW (2002) Anomalous concentrations of seismically triggered rock falls in Pacoima Canyon: are they caused by highly susceptible slopes or local amplification of seismic shaking? Bull Seismol Soc Am 92(8):3180-3189

Harp EL, Wilson RC (1995) Shaking intensity thresholds for rock falls and slides, evidence from 1987 Whittier Narrows and Superstition Hills earthquake strong-motion records. Bull Seismol Soc Am 85(6):1739-1757

Havenith HB, Torgoev I, Meleshko A, Alioshin Y, Torgoev A, Danneels G (2006) Landslides in the Mailuu-Suu valley, Kyrgyzstan: hazards and impacts. Landslides 3:137-147

Hsieh SY, Lee CT (2007) Empirical estimation of the Newmark displacement from the Arias intensity and critical acceleration. Eng Geol 122:34 42

Itasca (2006) Universal Distinct Element Code, user's guide. Itasca Consulting Group Inc., Minneapolis

Janbu N (1973) Slope stability computations, EmbankementsDam engineering, Casagrande Volume. Wiley, New York, pp 47-86

Jibson RW (1993) Predicting earthquake-induced landslide displacements using Newmark's sliding block analysis. Transp Res Rec 1411:9-17

Jibson RW (2007) Regression models for estimating coseismic landslide displacement. Eng Geol 91:209-218

Jibson RW, Harp EL, Michael JA (1998) A method for producing digital probabilistic seismic landslide hazard maps, an example from Los Angeles, California. U.S.G.S. Open-file Report 98-113.

Keefer DK (2002) Investigating landslides caused by earthquakes - a historical review. Surv Geophys 23(6):473-510

Kuhlmeyer RL, Lysmer J (1973) Finite element method accuracy for wave propagation problems. J Soil Mechanics \& Foundation Division 99(5):421-427

Kyrgyzgiiz. (1986). The report of the engineering studies in the surroundings of Mailuu-Suu City. Frunze, p. 90.

Lee W, Jennings P, Kisslinger C, Kanamori H (2003) International handbook of earthquake and engineering seismology, Part B. Academic Press, ISBN:978-0-12-440658-0.

Lee CT, Hsieh BS, Sung SH, Lin PS (2012) Regional Arias Intensity attenuation relationship for Taiwan considering VS30. Bull Seismol Soc Am 102(1):129-142

Lin C-W, Shieh C-L, Yuan B-D, Shieh Y-C, Liu S-H, Lee S-Y (2003) Impact of Chi-Chi earthquake on the occurrence of landslides and debris flows: example from the Chenyulan River watershed, Nantou, Taiwan. Eng Geol 71:49-61

Mahdavifar MR, Jafari MK, Zolfaghari MR (2007) The attenuation of Arias intensity in Alborz and Central Iran. Proceedings of the Fifth International Conference on Seismology and Earthquake Engineering, Tehran, Iran

Makdisi FI, Seed HB (1978) Simplified procedure for estimating dam and embankment earthquake-induced deformations. ASCE Journal of the Geotechnical Engineering Division 104:849-867
Maufroy E, Cruz-Atienza VM, Cotton F, Gaffet S (2015) Frequency-scaled curvature as a proxy for topographic siteeffect amplification and ground-motion variability. Bull Seismol Soc Am 105:354-367

Meunier P, Hovius N, Haines JA (2008) Topographic site effects and the location of earthquake induced landslides. Earth Planet Sci Lett 275:221-232

Miles SB, Ho CL (1999) Rigorous landslide hazard zonation using Newmark's method and stochastic ground motion simulation. Soil Dyn Earthq Eng 18:305-323

Minetti L, Pelli F, Stoutjesdijk J (2002) Technical review of Mailuu-Suu landslides and tailings problems and options for remediation. Technical Mission Report to the Kyrgyz Republic. 2002.

Moore ID, Grayson RB, Landson AR (1991) Digital terrain modeling: a review of hydrological, geomorphological and biological applications. Hydrol Process 5:3-30

Newmark N (1965) Effects of earthquakes on dams and embankments. Geotechnique 15:139-159

Nikitin RM, Fidelli IA (1974) Regional hydrological studies for the slope stability analyses on the case of Zeravshan River. Relation between surface and underground water 2:40-49

Parseval des Chênes MA (1806) Mémoire sur les séries et sur l'intégration complète d'une équation aux différences partielles linéaire du second ordre, à coefficients constants. Mémoires présentés à l'Institut des Sciences, Lettres et Arts, par divers savans, et lus dans ses assemblées. Sciences, mathématiques et physiques (Savans étrangers) 1:638-648

Peng WF, Wang CL, Chen ST, Lee ST (2009) A seismic landslide hazard analyses with topographic effect study in the 99 Peaks region, Central Taiwan. Environ Geol 57:537-549

Petley D, Dunning S, Rosser N, Kausar AB (2006) Incipient landslides in the Jhelum Valley, Pakistan following the 8th October 2005 Earthquake. Disaster Mitigation of Debris Flows, Slope Failures and Landslides. Universal Academy Press Inc, Tokyo, Japan, pp 47-55

Rajabi AM, Khamehchiyan M, Mahdavifar MR, Del Gaudio V (2010) Attenuation relation of Arias intensity for Zagros Mountains region (Iran). Soil Dyn Earthq Eng 30:110-118

Rathje EM, Antonakos G (2011) A unified model for predicting earthquake-induced sliding displacements of rigid and flexible slopes. Eng Geol 122:51-60

Rathje EM, Bray JD (2000) Nonlinear coupled seismic sliding analysis of earth structures. J Geotech Geoenviron 126:10021014

Rathje EM, Saygili G (2009) Probabilistic assessment of earthquake-induced sliding displacements of natural slopes. Bulletin of the New Zealand Society of Earthquake Engineering 42:18-27

Rathje EM, Faraj F, Russell S, Bray JD (2004) Empirical relationships for frequency content parameters of earthquake ground motions. Earthq Spectra 20:119-144

Romeo R (2000) Seismically-induced landslide displacements: a predictive model. Eng Geol 58(3-4):337-351

Sabetta F, Pugliese A (1996) Estimation of response spectra and simulation of nonstationary earthquake ground motions. Bull Seismol Soc Am 86(2):337-352

Saygili G, Rathje EM (2008) Empirical predictive models for earthquake-induced sliding displacements of slopes. J Geotech Geoenviron Eng ASCE 134(6):790-803 
Schlögel R, Torgoev I, de Marneffe C, Havenith HB (2011) Evidence of a changing distribution of landslides in the Kyrgyz Tien Shan, Central Asia. Earth Surf Process Landf 36(12):1658-1669

Seed HB, Martin GR (1966) The seismic coefficient in earth dam design. ASCE J Soil Mechanics and Foundations Division 92:25-58

Sepulveda SA, Murphy M, Petley DN (2005) Topographic controls on coseismic rock slides during the 1999 Chi-Chi earthquake, Taiwan. Journal of Engineering Geology and Hydrogeology 38:189-196

Sidle RC, Ochiai H (2006) Landslide analysis. In: Sidle RC, Ochiai H (eds) Landslides: processes, prediction and land use, water resources monograph 18. American Geophysical Union, Washington, D.C, pp 121-137

Stafford PJ, Berrill JB, Pettinga JR (2009) New predictive equations for Arias intensity from crustal earthquakes in New Zealand. J Seismol 13:31-52

Torgoev A, Havenith HB (2013b) Landslide susceptibility, hazard and risk mapping in Mailuu-Suu, Kyrgyzstan. In: Landslide science and practice. Springer, Berlin Heidelberg, pp 505510

Torgoev I, Alioshin YG, Havenith HB (2002). Impact of uranium mining and processing on the environment of mountainous areas of Kyrgyzstan. In: Merkel, Planer-Friedrich and Wolkersdorfer (eds) Uranium in the aquatic environment, Springer, Berlin Heidelberg New York, pp 93-98.

Torgoev A, Lamair L, Torgoev I, Havenith HB (2012) A review of recent case studies of landslides investigated in the Tien-Shan using microseismic and other geophysical methods. Proceedings of the International Symposium on Earthquake-Induced Landslides, Kiryu, Japan, pp 285-294

Torgoev I, Alioshin YG, Torgoev A (2013a) Monitoring landslides in Kyrgyzstan. FOG-Freiberg Online Geoscience 33:130-139
Torgoev A, Havenith HB, Lamair L (2013c). Improvement of seismic landslide susceptibility assessment through consideration of geological and topographic amplification factors. JAG 2013, 17-18/09 Grenoble, France.

Torgoev I, Niyazov R, Havenith HB (2013c) Tien-Shan landslides triggered by earthquakes in Pamir-Hindukush zone. Landslide Science and Practice: Complex Environment 5: 191-197

Travasarou T, Bray JD, Abrahamson NA (2003) Empirical attenuation relationship for Arias intensity. Earthquake Engineering \& Structural Dynamics 32:1133-1155

Trifonov VG, Makarov VI, Skobelev SF (1990) The TalasFergana active right-lateral fault. Geotectonics 24(5):435442

Vandenhove H, Quarch H, Clerc J, Lejeune J, Sweeck L, Sillen X, Mallants D, Zeevaert T (2003) Remediation of uranium mining and milling tailing in Mailuu-Suu district of Kyrgyzstan. TACIS Project NSCRE1/N³8 Report.

Wald DJ, Helmberger DV, Hartzell SH (1990) Rupture process of the 1987 Superstition Hills earthquake from the inversion of strong-motion data. Bull Seismol Soc Am 80:1079-1098

Wieczorek GF, Wilson RC, Harp EL (1985) Map showing slope stability during earthquakes in San Mateo County California. USGS Miscellaneous Investigations Map I-1257-E, scale 1: 62500 .

Wilson RC, Keefer DK (1985) Predicting areal limits of earthquake-induced landsliding. In: Ziony JI (ed) Evaluating Earthquake Hazards in the Los Ángeles Region: An Earth-Science Perspective, USGS Professional Paper, 1360: 317-345.

Yin Y, Wang F, Sun P (2009) Landslide hazards triggered by the 2008 Wenchuan earthquake, Sichuan, China. Landslides 6(2):139-152

Zeverbergen LW, Thorne CR (1987) Quantitative analysis of land surface topography. Earth Surf Process Landf 12:47-56 